\title{
INFLATION DYNAMICS
}

WITH LABOUR

MARKET MATCHING

\section{ASSESSING ALTERNATIVE SPECIFICATIONS}

by Kai Christoffel, James Costain, Gregory de Walque, Keith Kuester, Tobias Linzert, Stephen Millard and Olivier Pierrard 


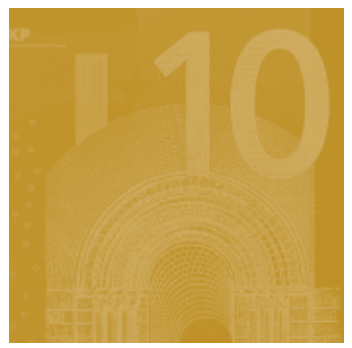

\title{
WORKING PAPER SERIES
}

NO I053 / MAY 2009

WAGE DYNAMICS

NETWORK

\section{INFLATION DYNAMICS WITH \\ LABOUR MARKET MATCHING}

\section{ASSESSING ALTERNATIVE SPECIFICATIONS}

\author{
by Kai Christoffel ${ }^{2}$, James Costain ${ }^{3}$, \\ Gregory de Walque ${ }^{4}$, Keith Kuester ${ }^{5}$, \\ Tobias Linzert ${ }^{2}$, Stephen Millard ${ }^{6}$ \\ and Olivier Pierrard ${ }^{7}$
}

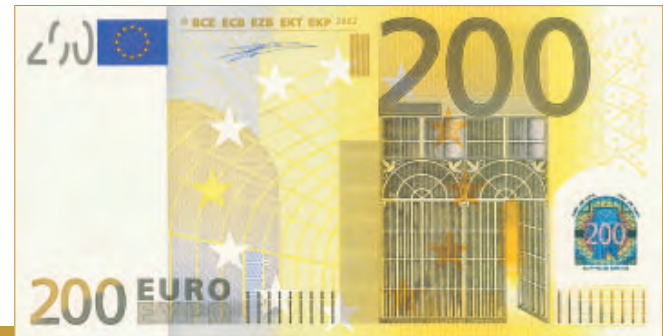

In 2009 all ECB

I The views expressed in this paper are those of the authors and do not necessarily reflect the views held by the European Central Bank, any other central bank in the Eurosystem, the Bank of England, the Federal Reserve Bank of Philadelphia or the Federal Reserve System. Without implication, we would like to thank Raf Wouters for taking the initiative in suggesting this project and participants in the Eurosystem Wage Dynamics Network for helpful comments.

2 European Central Bank, Kaiserstrasse 29, D-603II Frankfurt am Main, Germany; e-mail: kai.christoffel@ecb.europa.eu; tobias.linzert@ecb.europa.eu

3 Banco de España, Alcalá 50, E-28014 Madrid, Spain; e-mail: james.costain@bde.es 4 Banque Nationale de Belgique, Boulevard de Berlaimont 14, B-1000 Brussels, Belgium; e-mail: gregory.dewalque@nbb.be 5 Federal Reserve Bank of Philadelphia, Ten Independence Mall, Philadelphia, PA 19106-1574, USA; e-mail: keith.kuester@phil.frb.org 6 Bank of England, Threadneedle Street, London EC2R 8AH, UK e-mail: stephen.millard@bankofengland.co.uk 7 Banque Centrale du Luxembourg, 2 boulevard Royal, L-2983 Luxembourg, Luxembourg; e-mail: Olivier.Pierrard@bcl.lu 


\section{Wage Dynamics Network}

This paper contains research conducted within the Wage Dynamics Network (WDN). The WDN is a research network consisting of economists from the European Central Bank (ECB) and the national central banks (NCBs) of the EU countries. The WDN aims at studying in depth the features and sources of wage and labour cost dynamics and their implications for monetary policy. The specific objectives of the network are: i) identifying the sources and features of wage and labour cost dynamics that are most relevant for monetary policy and ii) clarifying the relationship between wages, labour costs and prices both at the firm and macro-economic level.

The WDN is chaired by Frank Smets (ECB). Giuseppe Bertola (Università di Torino) and Julian Messina (Universitat de Girona) act as external consultants and Ana Lamo (ECB) as Secretary.

The refereeing process of this paper has been co-ordinated by a team composed of Gabriel Fagan (ECB, chairperson), Philip Vermeulen (ECB), Giuseppe Bertola, Julian Messina, Jan Babecký (CNB), Hervé Le Bihan (Banque de France) and Thomas Mathä (Banque centrale du Luxembourg).

The paper is released in order to make the results of WDN research generally available, in preliminary form, to encourage comments and suggestions prior to final publication. The views expressed in the paper are the author's own and do not necessarily reflect those of the ESCB. 


\section{CONTENTS}

Abstract

Non-technical summary

1 Introduction and motivation

2 The baseline model

2.1 Households, consumption and saving

2.2 Firms

2.3 The labour market

2.4 Wage bargaining

2.5 Vacancy posting

2.6 Monetary policy, fiscal policy and market clearing

3 Stylised facts and the baseline economy

3.1 Calibration of the model economies

3.2 Stylised facts - the transmission of monetary policy

3.3 Effects of a monetary policy shock in the baseline

4 Right-to-manage bargaining

5 Wage rigidity

5.1 Efficient bargaining

5.2 Right-to-manage bargaining

6 Real rigidities arising within the individual firm

7 Contemporaneous hiring

8 Variants of the vacancy posting process

8.1 Employment adjustment costs convex in the hiring rate

8.2 Vacancy costs as sunk costs

9 On-the-job search

10 Endogenous job destruction

11 Conclusions

References

Appendix

European Central Bank Working Paper Series 


\begin{abstract}
This paper reviews recent approaches to modeling the labour market and assesses their implications for inflation dynamics through both their effect on marginal cost and on price-setting behaviour. In a search and matching environment, we consider the following modeling setups: right-to-manage bargaining vs. efficient bargaining, wage stickiness in new and existing matches, interactions at the firm level between price and wage-setting, alternative forms of hiring frictions, search on-the-job and endogenous job separation. We find that most specifications imply too little real rigidity and, so, too volatile inflation. Models with wage stickiness and right-to-manage bargaining or with firm-specific labour emerge as the most promising candidates.
\end{abstract}

JEL Classification System: E31,E32,E24,J64

Keywords: Inflation Dynamics, Labour Market, Business Cycle, Real Rigidities. 


\section{Non-Technical Summary}

The main task of central banks is to maintain price stability by controlling inflation and, for this reason, it is important to understand what drives the dynamics of inflation. A long tradition in monetary economics has assigned the labour market a central role in inflation dynamics. Not least given the wide diversity in labour market structures, institutions and policies across Europe, and the world more generally, it is of interest to know whether or not heterogeneity in certain aspects of the labour market matters for inflation dynamics and, hence, monetary policy.

This paper analyses and compares existing approaches to modelling the labour market, explaining their implications for the behaviour of inflation. The paper highlights which of the particular features of each modelling approach are most important for driving inflation dynamics and provides a structure to the rich variety of modelling approaches in previous work. In so doing, we follow an active strand of research that has set out explicitly to model individual workers and firms, who take time to form job matches. The rationale for so doing comes from the belief that the slow responses of employment and unemployment to changes in demand are a natural place to look for the origins of the slow response of inflation to changes in demand.

We start by examining what euro-area data suggests happens to labour market variables after an unexpected fall in interest rates (ie, a monetary policy shock). We find that output rises significantly above its steady state, that inflation rises, that wages per employee also rise but by less than output (in percentage terms), that employment rises significantly, and unemployment falls and, finally, that most of the adjustment in labour is borne by the number of employees rather than by hours worked per employee.

We then consider a standard macroeconomic model with unemployed workers looking for jobs, firms posting vacancies, and a clear distinction between employment and hours worked. Building on this, we replace certain assumptions about the labour market structure by others, one at a time. First, we consider alternative ways that firms and workers can decide on how many hours each worker works. Then, we consider the effect of wage negotiations being staggered, with wages fixed for some time and what happens when we, additionally, tie the wages of newly hired workers to those of existing workers in a firm. Next, we consider interactions at the firm-level between price and wage-setting. We then consider various types of hiring costs before moving on to consider search on-the-job, and finish by considering what happens when job destruction varies over the cycle. In each of the cases we provide intuition for the effect that a specific modification of the baseline model has on inflation dynamics.

We find that the baseline model predicts a response of inflation to changes in interest rates that is too large relative to the data. Allowing search on the job and considering different types of hiring cost does not seem to affect this result. However, when our baseline model is 
combined with the assumption that once employers and employees have agreed on an hourly wage, the employer chooses how many hours his employees will work, staggered wages help to smooth the reaction of wages resulting in a smaller response of inflation to an interest rate changes. Inflation responds even less when we account for the firm-specific nature of labour. But, in this case, the model also has implications for the responses of unemployment and vacancies that do not match the data.

More generally, by analysing a wide range of institutional features of the labour market, we show that only those institutional features that affect or generate a direct channel from wages to inflation matter for how inflation responds to interest rate changes. By contrast, institutional features that leave this channel unaffected matter much less for inflation dynamics. 


\section{Introduction and motivation}

The key task of central banks is to maintain price stability by controlling inflation, and, for this reason, it is important to understand what drives the dynamics of inflation. A crucial element of this is the underlying nature of nominal and real frictions associated with the adjustments of prices in the economy. A long tradition in monetary economics, starting with Phillips (1958), has assigned labour market frictions and, in particular wage-setting frictions, a central role in inflation dynamics. Not least given the wide diversity in labour market structures, institutions, and policies across Europe, and the world more generally, it is of interest to know whether heterogeneity in certain aspects of the labour markets matters for inflation dynamics and, hence, monetary policy.

This paper analyses and compares existing labour market modeling approaches within the New Keynesian business cycle model setup. In particular, it explains their implications for the behaviour of marginal cost and inflation in theory and quantitatively using a calibration with common parameters based on euro-area data. The paper highlights which of the particular features of each modeling approach are key for driving inflation dynamics and provides a structure to the rich variety of modeling approaches in the existing literature. ${ }^{1}$ We follow an active strand of research that has set out to model the labour market more explicitly within the New Keynesian business cycle model, most often opting for including variants of the Mortensen and Pissarides (1994) model of search and matching frictions. The rationale for so doing comes from the belief that sluggish responses in labour market variables to shocks are a natural place to look for the origins of the sluggish response of inflation to shocks. In terms of the New Keynesian framework, labour market frictions will alter either aggregate marginal cost or the firms' price-setting behaviour for a given marginal cost. ${ }^{2}$ However, so far, the implications for inflation dynamics seem to be mixed. Some have, for example, argued that accounting for equilibrium unemployment increases the resilience of marginal cost, and hence inflation, to shocks by adding a pool of slack resources; see, e.g., Trigari (2009) and Walsh (2005). Others, e.g., Krause and Lubik (2007), conclude that contrary to received wisdom wage rigidity does not have an effect on inflation inertia. ${ }^{3}$ As a starting point, we choose the efficient bargaining version of Trigari (2006): that

\footnotetext{
${ }^{1}$ Other papers, largely sparked by Shimer's (2005) critique, seek to improve the modeling or calibration of the labour market per se and are not necessarily concerned with nominal frictions, e.g., Gertler and Trigari (2006), Fujita and Ramey (2007), and Yashiv (2006). In this paper, we take up some of the suggestions made in these papers, since - through their implications for the behaviour of wages and unemployment - they also imply changes in the behaviour of real marginal cost.

${ }^{2}$ Thus, the labour market was seen as a source of 'real rigidities'. For an overview of the extensive literature on real rigidities more generally, see Woodford (2003).

${ }^{3}$ Another strand of literature has been concerned with normative implications, such as the design of optimal monetary policy; see, e.g., Blanchard and Gali (2006), Faia (2008), Tang (2006).
} 
is, a plain New Keynesian model with search and matching frictions and a distinction between heads and hours. Building on this, we replace certain assumptions on the labour market structure by others, one at a time. We consider the following variants: right-to-manage (instead of efficient) bargaining (Trigari (2006)), stickiness of wages in these setups (Gertler and Trigari (2006) and Christoffel and Linzert (2005)) differentiating between stickiness in new matches and existing matches (Bodart et al. (2005) and Bodart et al. (2006)), interactions at the firm-level between price and wage-setting (Kuester (2007), Sveen and Weinke (2007) and Thomas (2008)), alternative forms of vacancy posting costs (Yashiv (2006)) and the hiring process (Fujita and Ramey (2007)), search on-the-job (Krause and Lubik (2006) and van Zandweghe (2009)) and endogenous separation (den Haan et al. (2000) and Zanetti (2007)). In each of the cases we provide intuition for the effect that a specific modification of the baseline model has on inflation dynamics.

Our findings are as follows. We show, first, that the baseline model predicts a response of inflation that is too large relative to the data, as a result of the large and immediate response of real marginal cost. This would suggest either that the labour market is not an important source of real rigidities or that the specific way of modeling the labour market does not capture the way the labour market affects inflation dynamics in practice. We follow the second route. When combined with a 'right-to-manage' assumption for the determination of hours, staggered wages at the level of the match help to smooth the reaction of the marginal wage resulting, in a smaller response to shocks of marginal cost and inflation. Inflation responds even less to shocks when we account for the firm-specific nature of labour in the search and matching model. Doing so, however, also has implications for the responses of unemployment and vacancies that take these further away from the data. Variations of the hiring costs have only a small impact on inflation dynamics. In contrast, we find that endogenous separation may be a promising candidate for reducing the response of inflation to shocks, though this finding depends critically on the calibration, as is the case for many of the examples. More generally, by analysing a wide range of institutional features of the labour market employing a variety of variants of the Mortensen and Pissarides (1994) search and matvhing model, we show that only those institutional features that affect or generate a direct channel from wages to inflation matter for inflation dynamics. By contrast, institutional features that leave this channel unaffected matter much less for inflation dynamics.

The rest of the paper is structured as follows. In section 2, we lay out the baseline model. We highlight which features of the model will be changed subsequently. In section 3, we calibrate the baseline model to euro area data. Subsequently, we compare 
the responses of inflation (and wages and unemployment) to a monetary policy shock in the model with the responses to the same shock in euro area data. In section 4 we consider the effects of having 'right-to-manage' bargaining and section 5 adds nominal wage rigidities for new and existing jobs, exploring how these rigidities interact with the bargaining scheme. Section 6 considers what happens if wages and prices are set simultaneously in the presence of firm-specific labour. Section 7 allows for new hires being productive immediately and not only with a one-period delay. In section 8 we discuss the effects of varying the free-entry condition and vacancy costs. Sections 9 and 10 consider other margins along which adjustment can occur in the labour market: section 9 discusses on-the-job search and section 10 discusses endogenous job destruction. Section 11 concludes. An Appendix, as a point of reference, presents empirical evidence on monetary transmission in the euro area.

\section{The baseline model}

In this section we lay out our baseline model, a simplified version of Trigari's (2006) efficient bargaining model.

\subsection{Households, consumption and saving}

We assume that there is a continuum of workers indexed by $j$ on the unit interval who supply a homogeneous type of labour. Only a proportion $n_{t}$ of them are employed. We adopt a representative - or large - household interpretation so that the unemployment rate $u_{t}=1-n_{t}$ is identical at the household or at the aggregate level. As shown by Merz (1995) the representative household assumption amounts to allowing for the existence of state-contingent securities offering workers insurance against differences in their specific labour income. Household members (workers) share their labour income, i.e., wage and unemployment benefits, before choosing per capita consumption and bond holdings. Labour income is made of the sum of hourly wages, $w_{t}$, weighted by total hours worked, $n_{t} h_{t}$, and unemployment benefits, $b$, weighted by the number of unemployed, $1-n_{t} \cdot{ }^{4}$ As shareholders, households also receive the profits $\Psi_{t}$ generated by the monopolistic competitive retail firms and the intermediate producers of labour services.

We assume separability between leisure and consumption in the instantaneous utility function, implying that all workers share the same marginal utility of wealth and choose the same optimal consumption, be they employed or not. A worker's utility can be

\footnotetext{
${ }^{4} b$ could alternatively be interpreted as the income generated by the domestic activities of an unemployed worker.
} 
written as

$$
\mathcal{U}\left(c_{j t}, h_{j t}\right)=\frac{c_{j t}^{1-\sigma_{c}}}{1-\sigma_{c}}-\chi \frac{h_{j t}^{1+\phi}}{1+\phi}
$$

with $\sigma_{c} \geq 1, \chi>0, \phi \geq 0$. Let $\mathcal{H}_{t}(j)$ be the value function of worker $j$. If we momentarily leave aside the labour supply decision, which is taken by the household as a whole, worker $j$ 's maximisation program is

$$
\mathcal{H}_{t}(j)=\max _{c_{j t}, B_{j t+1}}\left\{\mathcal{U}\left(c_{j t}, h_{j t}\right)+\beta \cdot \mathrm{E}_{t} \mathcal{H}_{t+1}(j)\right\}
$$

subject to

$$
\frac{B_{t}}{r_{t} p_{t}}+c_{t}+t_{t}=\frac{B_{t-1}}{p_{t}}+n_{t} w_{t} h_{t}+\left(1-n_{t}\right) b+\Psi_{t}
$$

where workers hold their financial wealth in the form of one-period bonds, $B_{t}$, with price $1 / r_{t}$ (where $r_{t}$ is the nominal interest rate), $c_{t}$ represents aggregate consumption, $t_{t}$ are lump-sum taxes payable and $p_{t}$ is the consumer price index.

The worker's optimal consumption and saving decision coincide with those of his peers and are derived from the following first-order conditions:

$$
\begin{aligned}
\frac{\lambda_{t}}{p_{t}} & =\beta r_{t} \mathrm{E}_{t}\left\{\frac{\lambda_{t+1}}{p_{t+1}}\right\} \\
\lambda_{t} & =c_{t}^{-\sigma_{c}}
\end{aligned}
$$

\section{$2.2 \quad$ Firms}

In our baseline model, the economy consists of three sectors: a perfectly competitive final good sector, a monopolistically competitive retail sector and a perfectly-competitive intermediate good sector.

\subsubsection{Final goods sector}

We assume a continuum of differentiated goods indexed by $i$ on the unit interval. Final good firms aggregate the differentiated goods $y_{t}(i)$ produced by the retailers into a homogeneous consumption good using a Dixit-Stiglitz technology

$$
y_{t}=\left[\int_{0}^{1}\left[y_{t}(i)\right]^{\mu_{p}} d i\right]^{1 / \mu_{p}} \text { with } \mu_{p} \in(0,1)
$$

where $1 / \mu_{p}$ represents the retailers' gross price mark-up while $1 /\left(1-\mu_{p}\right)$ is the elasticity of substitution between intermediate differentiated goods. Each final good firm 
maximises profit, leading to the following demand for intermediate good $i$

$$
y_{t}(i)=\left(\frac{p_{t}(i)}{p_{t}}\right)^{\frac{1}{\mu_{p}-1}} y_{t}
$$

where $p_{t}$ is the final good price, obtained by aggregation of the retailers' prices

$$
p_{t}=\left[\int_{0}^{1}\left[p_{t}(i)\right]^{\frac{\mu_{p}}{\mu_{p}-1}} d i\right]^{\frac{\mu_{p}-1}{\mu_{p}}}
$$

The modeling of the final good sector will remain unchanged throughout the paper.

\subsubsection{Monopolistic retailers and price setting}

Given the demand $y_{t}(i)$ retail firm $i$ faces for its product, it buys a homogeneous intermediate labour good at nominal price $p_{t} x_{t}$ per unit and transforms it one for one into a differentiated product. In each period, a fraction $1-\xi_{p}$ of retail firms sets a new price $p_{t}^{*}(i)$. This price prevails $j$ periods later with probability $\xi_{p}^{j}$. The pricesetting firms maximise the discounted flows of expected real profits using a discount rate consistent with that used by their shareholders (i.e., households). All the pricesetting firms face the same optimisation problem, implying that they all choose the same new price $p_{t}^{*}$. Profit maximisation results in the following first-order condition

$$
\mathrm{E}_{t} \sum_{j=0}^{\infty} \beta_{t, t+j}\left(\xi_{p}\right)^{j} \frac{y_{t+j}(i)}{p_{t+j}}\left(p_{t}^{*}-\frac{1}{\mu_{p}} p_{t+j} x_{t+j}\right)=0,
$$

where $\beta_{t, t+j}:=\beta^{j} \frac{\lambda_{t+j}}{\lambda_{t}}$ denotes the stochastic discount factor. Log-linearising the resulting expression around the steady state enables us to derive the New Keynesian Phillips curve

$$
\hat{\pi}_{t}=\beta \mathrm{E}_{t} \hat{\pi}_{t+1}+\frac{\left(1-\xi_{p}\right)\left(1-\beta \xi_{p}\right)}{\xi_{p}} \hat{x}_{t},
$$

where $\pi_{t}=p_{t} / p_{t-1}$ is the inflation rate while 'hats' denote percentage deviations from steady state. This expression makes clear that, for a given response of inflation to movements in real marginal cost - which will depend on $\xi_{p}$ - the response of inflation to a given shock will depend on how real marginal cost, $\hat{x}_{t}$, responds to that shock.

\subsubsection{Intermediate goods sector}

In the baseline model, there are a continuum of intermediate labour good producers uniformly distributed and selling their output in a competitive market. Their only 
factor of production is labour, and labour efficiency is decreasing with hours, so that $h$ hours supplied by one worker produce only $h^{\alpha}$ units of efficient labour, $\alpha<1$. Following Mortensen and Pissarides (1999), we assume that intermediate producers can hire at most one worker so that their production is either zero or

$$
y_{t}^{l}(o)=\left[h_{t}(o)\right]^{\alpha} \text { with } \alpha<1 \text {, }
$$

where $o$ indicates match $o$. In the baseline the intermediate goods sector and the retailers are linked through competitive markets for the intermediate good. In section 6 , we assess the implications for inflation dynamics once these two sectors are merged so that there are interactions between wage and price setting at the level of the individual firm.

\subsection{The labour market}

The labour market is organised such that it links the intermediate good firms and the workers.

\subsubsection{Labour market flows}

Let $m_{t}$ denote the number of new firm-worker matches. We assume that the number of matches is a function of the number of job vacancies $v_{t}$ and effective job seekers $u_{t}$, and we consider the following linear homogeneous matching function:

$$
m_{t}=\sigma_{m} u_{t}^{\vartheta} v_{t}^{1-\vartheta}
$$

with $\sigma_{m}>0$ and $\vartheta \in(0,1) .{ }^{5}$ In the baseline, the probability an unemployed worker finds a job is given by

$$
s_{t}=\frac{m_{t}}{u_{t}}
$$

while the probability that a firm fills a vacancy is given by

$$
q_{t}=\frac{m_{t}}{v_{t}}
$$

An exogenous proportion $\rho$ of firm-worker relationships ends each period, which implies the following employment dynamics:

$$
n_{t}=(1-\rho) n_{t-1}+m_{t-1} .
$$

\footnotetext{
${ }^{5}$ Models with search on-the-job (section 9) modify the matching function to depend also on the number of employed workers seeking jobs.
} 
In the baseline therefore employment is predetermined, while hours per worker are free to adjust contemporaneously. This means that marginal costs are in the first period after a shock influenced exclusively by the marginal cost of an additional hour worked on the intensive margin. We ease this assumption in section 7 , where we allow for contemporaneous hiring, and in section 10, which looks at endogenous separation.

\subsubsection{Value of a job and of a vacancy for an intermediate labour-services producer}

Firms and workers bargain over wages; such bargaining distributes the rents that arise once a match is formed to both the firm and the worker. We denote by $J_{t}$ and $V_{t}$, respectively, the asset value of a job and of a vacancy at period $t$, dropping match index $i$ for convenience:

$$
\begin{aligned}
J_{t} & =y_{t}^{l} x_{t}-h_{t} w_{t}+\mathrm{E}_{t}\left\{\beta_{t, t+1}(1-\rho) J_{t+1}\right\}, \\
V_{t} & =-k_{t}^{v}+\mathrm{E}_{t}\left\{\beta_{t, t+1}\left[q_{t} J_{t+1}+\left(1-q_{t}\right) V_{t+1}\right]\right\},
\end{aligned}
$$

where $k_{t}^{v}$ represents the per-period hiring cost (in units of the consumption good).

\subsubsection{Value of a job and value of unemployment for a household}

For a worker's family, which bargains on his behalf, the value of a new job is given by

$$
W_{t}=h_{t} w_{t}-\frac{\chi}{\lambda_{t}} \frac{h_{t}^{1+\phi}}{1+\phi}+\mathrm{E}_{t}\left\{\beta_{t, t+1}\left[(1-\rho) W_{t+1}+\rho U_{t+1}\right]\right\}
$$

where $U_{t}$ represents the present value of being unemployed at period $t$. Formally,

$$
U_{t}=b+\mathrm{E}_{t}\left\{\beta_{t, t+1}\left[s_{t} W_{t+1}+\left(1-s_{t}\right) U_{t+1}\right]\right\}
$$

\subsection{Wage bargaining}

In this section, we discuss the bargaining over wages and hours between workers and firms once a match has been formed. We will focus here on a bargaining scheme that leads to Pareto-efficient outcomes. Hours and wages are bargained over simultaneously and the bargained wage and hours maximise the joint surplus of the firm and the worker. ${ }^{6}$ The outcome of the bargaining process is obtained by maximisation of the

\footnotetext{
${ }^{6}$ Also, in the baseline we abstract from any wage rigidity. We will look at a different, right-tomanage bargaining scheme in section 4 , and in section 5 we will analyse what real wage rigidity means for inflation and unemployment dynamics under the respective bargaining schemes.
} 
Nash product:

$$
\max _{w_{t}, h_{t}}\left(W_{t}-U_{t}\right)^{\eta}\left(J_{t}-V_{t}\right)^{1-\eta} .
$$

The first term of the Nash product is the surplus a worker obtains from a job, raised to the worker's relative bargaining power $\eta \in(0,1)$. The second term is the firm surplus, raised to the firm's relative bargaining power $1-\eta$.

Under efficient bargaining, the first-order conditions can be shown to simplify to

$$
\frac{\chi}{\lambda_{t}} h_{t}^{\phi}=x_{t} \alpha h_{t}^{\alpha-1}=\alpha \frac{x_{t} y_{t}^{l}}{h_{t}}
$$

This shows that the wage paid in any individual matches is not allocative for hours in existing matches, that is $\partial h_{t} / \partial w_{t}=0$. Note that $x_{t}$, the price of the intermediate goods, coincides with the marginal cost for price-setting firms. Rearranging the above equation

$$
x_{t}=\frac{\chi \frac{h_{t}^{\phi}}{\lambda_{t}}}{\alpha h_{t}^{\alpha-1}} \equiv \frac{m r s_{t}}{m p l_{t}}
$$

highlights the implications of efficient bargaining for marginal costs (and inflation). Real marginal cost will equal the worker's marginal rate of substitution between consumption and leisure $\left(m r s_{t}\right)$ divided by the real marginal product of labour $\left(m p l_{t}\right)$. Both of these will, in turn, depend on hours worked per employee. Efficiency requires that the marginal gain to the firm of an additional hour worked (the firm's marginal value product of labour, $x_{t} m p l_{t}$ ) is the same as the marginal cost to the worker of that hour (his marginal rate of substitution between consumption and leisure, $m r s_{t}$ ). This makes clear that this subjective price of work determines the marginal wage, the marginal cost of producing intermediate goods and the marginal cost of producing differentiated goods. Note that, in contrast, the average hourly wage rate, $w_{t}$, does not measure marginal costs in the above setup. ${ }^{7}$

This bargaining procedure maximises the joint surplus of the match, that is $J_{t}+W_{t}-$ $U_{t}-V_{t}{ }^{8}$ The first-order condition for the wage bargaining simplifies to

$$
\eta\left(J_{t}-V_{t}\right)=(1-\eta)\left(W_{t}-U_{t}\right)
$$

which states that each of the contracting parties receives a share of the total surplus

\footnotetext{
${ }^{7}$ The marginal cost here is determined by having an employed worker work for an additional hour, while the average wage rate averages over all hours worked (including the infra-marginal hours).

${ }^{8}$ Note that all terms in the wage cancel in the joint surplus of workers and firms since the wage is not allocative in efficient bargaining.
} 
proportional to its relative bargaining power.

\subsection{Vacancy posting}

In order to find a worker, and so in order to produce, labour firms have to post a vacancy first. In the baseline we follow Mortensen and Pissarides (1999) and Merz (1995), and assume a constant, per period, cost of opening up a vacancy, $k_{t}^{v}=\kappa \cdot{ }^{9}$ Free entry in the market for vacancies implies that in equilibrium the value of a vacancy is $V_{t}=0$ in every period $t$ and the equation for the asset value of a vacancy (15) can be recast as:

$$
\kappa=q_{t} \mathrm{E}_{t}\left\{\beta_{t, t+1} J_{t+1}\right\}
$$

where total vacancy costs are given by $\kappa v_{t}$, and the average cost per hiring is $\kappa / q_{t}$. Using this, the value of a job for a firm simplifies to

$$
J_{t}=y_{t}^{l} x_{t}-h_{t} w_{t}+(1-\rho) \frac{\kappa}{q_{t}} .
$$

From equations (22) and (23), one easily obtains the dynamic representation of the average cost per hire

$$
\frac{\kappa}{q_{t}}=\mathrm{E}_{t}\left\{\beta_{t, t+1}\left[y_{t+1}^{l} x_{t+1}-h_{t+1} w_{t+1}+(1-\rho) \frac{\kappa}{q_{t+1}}\right]\right\}
$$

which determines job creation in the model.

\subsection{Monetary policy, fiscal policy and market clearing}

Throughout the paper we assume that monetary policy is conducted according to the following Taylor rule

$$
\hat{r}_{t}=\rho_{r} \hat{r}_{t-1}+\left(1-\rho_{r}\right) \delta_{\pi} \hat{\pi}_{t-1}+\zeta_{t}^{m}
$$

with $\rho_{r} \geq 0$ and $\delta_{\pi}>1$ and $\zeta_{t}^{m}$ is an i.i.d. interest rate shock. ${ }^{10}$ Lump-sum taxes, $t_{t}$, are set so as to balance the budget period by period and there is no autonomous

\footnotetext{
${ }^{9}$ We look at alternative assumptions about vacancy posting costs in section 8 .

${ }^{10}$ The Taylor rule that we use in this paper requires only lagged information. It is therefore implementable. A further advantage of using this specification is that the initial reaction of nominal rates to a monetary easing is the same in all the model variants that we discuss. We include only inflation and lagged rates in the Taylor rule. This ensures that the nominal rate is not directly influenced by differences in the output dynamics, which improves comparability across model variants.
} 
government spending. Finally, equilibrium in the final goods market implies ${ }^{11}$

$$
y_{t}=c_{t}
$$

\section{Stylised facts and the baseline economy}

The aim of this paper is to elicit the role of specific labour market frictions for the behaviour of marginal cost and inflation. In order to obtain a measure of the empirical relevance of the respective approaches, we compare the responses to a monetary policy easing in the respective model variant to stylised facts for the euro area.

\subsection{Calibration of the model economies}

In order to put all variants on the same footing, the calibration is harmonised as much as possible. The calibration largely follows Christoffel et al. (2009) and matches salient features of the euro area between 1984 and 2006. Table 1 presents the assigned common parameter values.

The time-discount factor, $\beta$, is chosen to match an average annual real rate of $3.3 \%$. We set $\phi$ to 10 , implying an elasticity of substitution for labour of 0.1 , in line with but at the lower end of - microeconomic studies for the euro area. ${ }^{12}$ The value of the risk aversion coefficient is set to $\sigma_{c}=1.5$, following Smets and Wouters (2003).

Turning to the labour good sector and the labour market, we set $\alpha=0.99$, so there are almost constant returns to hours per employee. ${ }^{13}$ On monthly data ranging to the early 1990s, Burda and Wyplosz (1994) estimate an elasticity of matches with respect to unemployment of $\vartheta=0.7$ for France, Germany and Spain. Petrongolo and Pissarides (2001) survey estimates of the matching function for European countries and for the United States and conclude that a range from $\vartheta=0.5$ to $\vartheta=0.7$ is admissible. We select the midpoint, setting $\vartheta=0.6$. The bargaining power of workers is set to a conventional value: $\eta=0.5$.

For the variants of the model we consider later that involve wage stickiness, we follow the recent evidence of du Caju et al. (2008), which reports average wage contract

\footnotetext{
${ }^{11}$ We assume that vacancy posting costs are taxes that are rebated lump-sum to the consumers and that do not require real ressources. This simplifies the comparability of the different modelling variants.

${ }^{12}$ The elasticity of inter-temporal substitution of labour, $1 / \phi$, is small in most microeconomic studies (between 0 and 0.5) for the euro area; for details, see Evers, Mooij, and Vuuren (2005), who report statistics based on a meta sample as well as estimates based on Dutch data.

${ }^{13}$ Our model does not contain capital. In some of the variants, there is thus a trade-off between obtaining a reasonable labour share (of around 60\%) and small ex post profits associated with jobs. We opt to fit the latter and choose $\alpha=0.99$ instead of a lower value.
} 


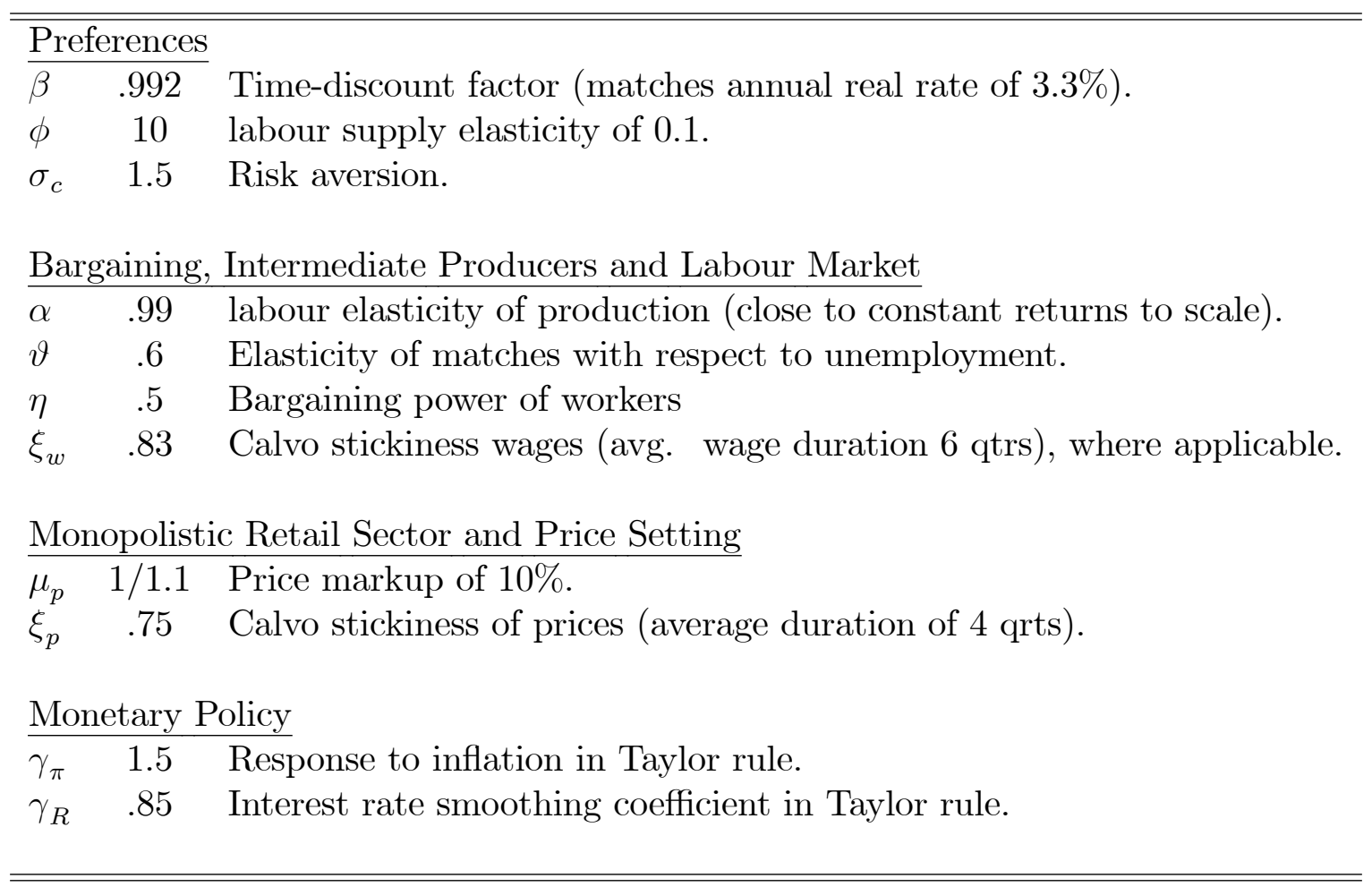

Table 1: PARAmeters And Their CALIBRATED VAlues. The table reports calibrated parameter values that are identical over the different modeling approaches. The model is calibrated to the euro area from 1984Q1 to 2006Q4.

durations for various euro area countries of between one and three years. Where applicable, we therefore set the degree of nominal wage rigidity to $\xi_{w}=0.83$, which implies an average wage duration of 6 quarters.

In the price-setting sector, we calibrate the markup to a conventional value of $10 \%$, so $\mu_{p}=1 / 1.1$ (in the Dixit-Stiglitz setup this implies a price-elasticity of demand of $\epsilon=11)$. For the average contract duration of prices we use the results of Alvarez et al. (2006) and set the corresponding Calvo parameter to $\xi_{p}=0.75$, which amounts to an average price duration of 4 quarters. As is conventional, we set the response of monetary policy to inflation to $\gamma_{\pi}=1.5$ and allow for interest rate smoothing by setting $\gamma_{R}=0.85$.

Given these parameters, we set the other parameters of our models to ensure that the steady-state values for certain endogenous variables coincided across the different setups. The target values for these variables, shown in Table 2, thereby implicitly define the values of the remaining model parameters.

The steady-state unemployment rate is targeted to be $u=9 \%$, in line with the average of the euro area unemployment rate over the sample 1984 to 2006 . We target a probability of finding a worker for an open vacancy of $q=0.7$, in line with the euro area evidence collected in Christoffel et al. (2009). Our target for steady-state hours 


\begin{tabular}{ccl}
\hline \hline & Value & Explanation \\
\hline$u$ & $9 \%$ & Unemployment rate \\
$q$ & $70 \%$ & Probability of finding a worker \\
$h$ & 1 & Hours worked per employee. \\
$\frac{b}{w h}$ & $65 \%$ & Unemployment benefits replacement rate. \\
$\rho$ & .06 & Quarterly separation rate. \\
\hline \hline
\end{tabular}

Table 2: CAliBration TARGets. The table reports calibrated parameter values. The model is calibrated to the euro area from 1984Q1 to 2006Q4.

worked per employee is $h=1$. We set the replacement income $b$ so as to ensure that the replacement rate in steady state in each of the variants, $\frac{b}{w h}$, equals $65 \%$, in line with the net replacement rates published by the OECD in its set of 'Benefits and Wages' data. Finally, the evidence collected in Christoffel et al. (2009) and Hobijn and Sahin (2007) points to quarterly separation rates, from a worker flow perspective, of $\rho=6 \%$.

\subsection{Stylised facts - the transmission of monetary policy}

In response to a monetary shock that causes interest rates to fall by 100 basis points in annualised terms, empirical evidence from the literature and our own VAR (see Appendix) shows that in the euro area: ${ }^{14}$

Fact 1: output rises significantly above its steady state. Depending on the study the peak response varies between 0.3 and 0.7 percentage point.

Fact 2: inflation rises. The peak increase in year-on-year inflation lies between 0.2 and 0.3 percentage point.

Fact 3: wages per employee also rise but by less than output (in percentage terms).

Fact 4: employment rises significantly, and unemployment falls. Unemployment falls by $3 \%$ to $4.5 \%$ (number of heads), and the unemployment rate falls by 0.25 to 0.4 percentage point.

Fact 5: most of the adjustment in labour is borne by the number of employees rather than by hours worked per employee. Some uncertainty surrounds this statement,

\footnotetext{
${ }^{14}$ While significant differences exist in the microstructure of the economy, and the labour market in particular, between the euro area and the United States the above stylised facts happen to be consistent also with the evidence for the United States, e.g., Christiano et al. (2005), Angeloni et al. (2003) and Trigari (2005).
} 
though, as the data for hours worked in the euro area are of relatively poor quality. ${ }^{15}$

In the following, we assess each of the different modeling variants against these five stylised facts.

\subsection{Effects of a monetary policy shock in the baseline}

As a first check against this evidence, Figure 1 reports the response of the economy to a monetary easing, where the impulse is an exogenous one percentage point reduction in the nominal interest rate. As can be seen in Figure 1, in the baseline inflation responds far too strongly to the monetary easing (by a factor of ten) while output effects are of the appropriate size. The strong response of inflation comes from the fact that real marginal costs for price setting firms are largely determined by the cost of increasing hours worked by each worker. Under efficient bargaining, the baseline case, these marginal costs are given by the marginal rate of substitution divided by the marginal product of labour, $x_{t}=\frac{m r s t}{m p l_{t}}$. Given near constant returns to scale ( $\alpha$ close to unity), the marginal product of labour, $m p l_{t}$, will be little affected. The percentage change in real marginal cost will therefore be driven by the response of the marginal rate of substitution, $m r s_{t}$. This in turn depends on the percentage change in the marginal utility of consumption and, fundamentally, on the response of hours per worker, where the latter is amplified $\phi$ times. Given our calibration, this implies a strong response of real marginal cost to an increase in hours worked and output. ${ }^{16}$

The remainder of the paper alters features of the model that affect the response of inflation to shocks. We start by assessing a different bargaining scheme.

\section{Right-to-manage bargaining}

In this section, we consider an alternative process for bargaining over wages and hours. In particular, we follow Trigari (2006) and use a 'right-to-manage' assumption for the

\footnotetext{
${ }^{15}$ For example, no quarterly series for actual hours worked exists for the euro area, or individually for all its member states. The measured response of hours worked (and hours per worker) therefore naturally is based on proxy series; cp. Appendix A.

${ }^{16}$ While the average wage rate does not have a direct bearing on inflation, there is an indirect effect. Employment and unemployment are determined by the job creation condition, (24). As illustrated in Figure 1, in the baseline model the real wage response to the monetary policy shock is large. Trigari (2006) highlights that solving the Shimer (2005) puzzle in the benchmark model also helps to reduce the response of inflation. If more of the labour adjustment needed to produce the additional output is provided through the extensive (number of employees) margin, the intensive (hours per employee) margin will also react less, which curbs the rise in the marginal rate of substitution and thus the rise in marginal costs.
} 
bargaining process. In this setup, the wage rate is agreed upon first and then the firm is free to choose hours worked at that wage rate so as to maximise profits. The same wage rate applies to marginal and inframarginal hours worked. This setting seems reasonable for a number of wage contracts. In addition, it also preserves much of the empirically successful structure of the New Keynesian model. ${ }^{17}$ The first-order condition for labour

demand is:

$$
x_{t} \alpha h_{t}^{\alpha-1}=w_{t} \Longleftrightarrow x_{t}=\frac{w_{t} h_{t}}{\alpha y_{t}^{l}}=\frac{w_{t}}{m p l_{t}} .
$$

meaning that the cost of the marginal hour is equal to its benefits, i.e., that the hourly wage is equal to the marginal value product of an hour worked. The right-tomanage assumption radically modifies the composition of real marginal cost. Under efficient bargaining, real marginal cost depends on hours and the marginal utility of consumption. Under right-to-manage, the hourly wage becomes an essential element of real marginal cost, opening what Christoffel et al. (2009) and Trigari (2006), for example, term the 'wage channel'. Therefore, the response of marginal cost and inflation to shocks will depend entirely upon the response of the bargained hourly wage to shocks. ${ }^{18}$

This notwithstanding, the effect of the right-to-manage assumption on marginal cost and inflation in equilibrium is a priori unclear. The major difference to the efficient bargaining assumption is that the choice of hours depends directly on the average wage, and that $\partial h_{t} / \partial w_{t}<0$. This affects the wage bargaining. Wage equation (21) becomes

$$
\eta \Omega_{t}\left(J_{t}-V_{t}\right)=(1-\eta)\left(W_{t}-U_{t}\right)
$$

with

$$
\Omega_{t}=\frac{1}{1-\alpha}\left(\frac{m r s_{t}}{x_{t} m p l_{t}}-\alpha\right)=\frac{1}{1-\alpha}\left(\frac{\chi h_{t}{ }^{1+\phi-\alpha}}{\alpha \lambda_{t} x_{t}}-\alpha\right)
$$

This means that the relative bargaining power of the workers in the wage negotiation is modified by $\Omega_{t}$ : equations (28) and (29) suggest that the workers' bargaining power increases with hours worked. ${ }^{19}$ The more inelastic the labour supply at the intensive

\footnotetext{
${ }^{17}$ Following Erceg et al. (2000), when modeling wage rigidities the literature typically assumes that monopolistically competitive labour firms produce an intermediate labour good. The assumption is that these firms set wages (the equivalent to the wage rate here) in a staggered manner and let labour output and thus input of hours into labour-good production (the equivalent to hours per employee here) be demand-determined.

${ }^{18}$ This does not, of course, mean that the marginal rate of substitution plays no role in inflation dynamics under right-to-manage. There is still an indirect influence of the marginal rate of substitution on inflation through its effect on the bargained wage.

${ }^{19}$ If we keep the free-entry assumption and constant recurrent vacancy posting costs, equation (22) still holds. The value of a job for a firm (23) and the dynamic of the average cost per hiring (24) can be simplified by replacing $x_{t} y_{t}^{l}$ by $h_{t} w_{t} / \alpha$.
} 
margin (the larger is $\phi$ ), the stronger this effect. If $\phi$ is large enough, the average wage will tend to be more responsive under right-to-manage than under efficient bargaining because of the strong relative bargaining power effect. It is less clear, however, whether this also implies that marginal costs are more responsive. Under right-to-manage, the marginal wage coincides with the average wage, $w_{t}$, which is more responsive than the average wage would be under efficient bargaining. Under efficient bargaining, however, the marginal wage, given by $m r s_{t}$, is already more responsive than the average wage.

Figure 1 compares the response of the economy to a monetary shock under both bargaining schemes. As the above logic suggests, the average hourly wage rate, $w_{t}$, responds more strongly (and in fact much too strongly in view of the stylised facts) to a monetary easing under right-to-manage. Still, the marginal wage rates (which determine the marginal cost of firms) show a very similar movement under both bargaining schemes, as can be seen in the similar response of marginal cost under the two schemes, leaving the response of inflation to a monetary policy shock essentially unchanged. $^{20}$ We conclude that the bargaining scheme in itself has little implication for inflation dynamics. As the next section shows, however, different bargaining schemes can imply fundamentally different effects of wage rigidity on inflation dynamics.

\section{Wage rigidity}

A cornerstone of the canonical New Keynesian framework is that average wage rates and their stickiness are instrumental for inflation dynamics; see, e.g., Christiano et al. (2005). This section of the paper discusses the role of wage stickiness for inflation dynamics once search and matching frictions in the labour market are accounted for. The related New Keynesian literature is Trigari (2006), Christoffel and Linzert (2005), Christoffel and Kuester (2008), and Krause and Lubik (2007).

In the model, the role of wage stickiness for inflation dynamics depends on the type of wage bargaining along which the model economy is organised (efficient vs. rightto-manage) as well as on whether wage stickiness affects only existing matches or also new matches (and thus hiring incentives of firms). We assume that in each period only a fraction $\left(1-\xi_{w}^{o}\right)$ of all existing wage contracts is renegotiated. New hires are paid

\footnotetext{
${ }^{20}$ The different response in the average wage rate caused by the bargaining power effect does, however, imply differences in the response of unemployment. The average wage rate responds by more under right-to-manage and thus leaves relatively less of the increased revenue in the hands of the firms, thereby reducing hiring incentives. As a consequence, this leads to a smaller response of employment under right-to-manage than under efficient bargaining. This in turn leads to slightly more recourse to the intensive margin under right-to-manage than under efficient bargaining, which reinforces the increase in the wage and thus marginal costs.
} 

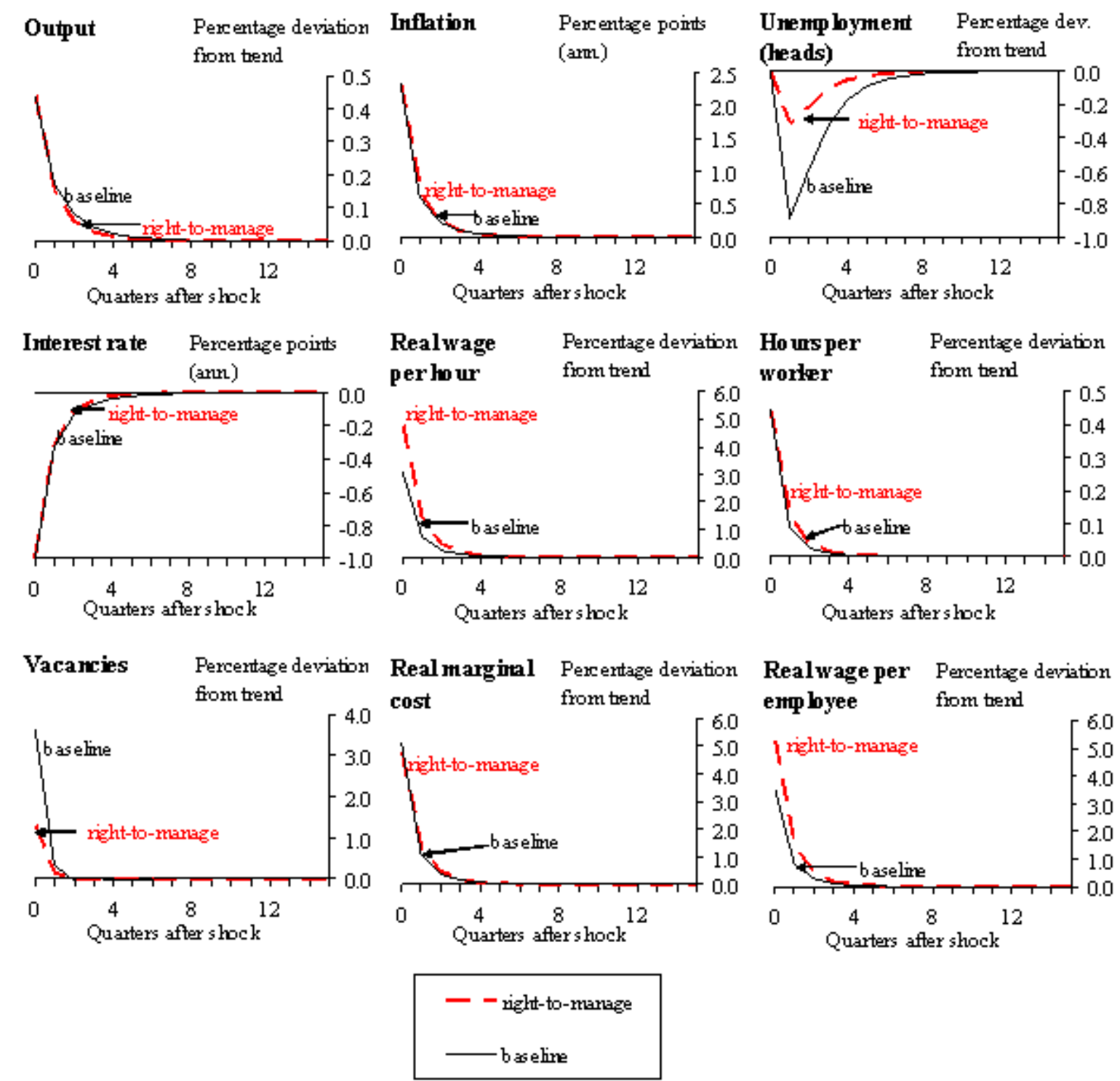

Figure 1: Impulse ReSPONSES to A MONETARY EASing - BASEline Vs. RightTO-MANAGE. Shown are impulse responses to an unanticipated 100 bps reduction in the quarterly nominal interest rate in quarter 0 . All entries are in percentage deviations from steady state. Interest rates and inflation rates are reported in annualized terms. The black solid line marks the baseline response with efficient bargaining. The red dashed line shows the response under right-to-manage bargaining. 
either the existing nominal contract wage from the previous period (with respective probabilities $\xi_{w}^{n}$ ) or they freely negotiate the wage (with probability $1-\xi_{w}^{n}$ ). Full nominal wage flexibility obtains if $\xi_{w}^{o}=\xi_{w}^{n}=0 .{ }^{21}$

Even though the wage bargaining will be discussed in detail later, it is important at this stage to stress that all the 'firm-worker' pairs that are given the opportunity to (re)-negotiate their wage contract face the same problem and therefore set the same wage. Because wage negotiation is time-dependent, different workers may be paid different wages and can supply different hours, even though they are otherwise ex-ante identical.

\subsection{Efficient bargaining}

Under efficient bargaining, as we showed earlier, real marginal cost will equal the workers' marginal rate of substitution divided by their marginal product and will be independent of the average wage rate in existing matches. ${ }^{22}$ For that reason, wage rigidity, if it only affects existing matches, does not have a bearing on inflation dynamics if bargaining is efficient.

Matters change if wage stickiness affects the wages of prospective new hires. As the vacancy posting condition equation makes clear, hiring incentives depend on the expected profits of firms. Wages are important in allocating the surplus of the match among firms and workers. As Hall (2005) notes, wage stickiness in new matches enhances the cyclicality of job creation by altering the share of revenue left to firms over the cycle. Since hiring incentives are affected, future marginal costs and, thus, inflation will be affected as well. The reason is that the hiring behaviour of firms influences the economy-wide relative use of the extensive margin and the intensive margin of employment and this will have a direct bearing on marginal costs, as a result of the decreasing returns to hours worked per employee, $\alpha \leq 1$, and the increasing marginal disutility of work $\phi>0 .{ }^{23}$ Wage stickiness, insofar as it affects new matches,

\footnotetext{
${ }^{21}$ These matches draw a wage from the previous period's wage distribution. The rationale for this assumption, following Gertler and Trigari (2006), lies in interpreting a match as one position in a multiworker firm. While every period there may be new hires for some positions, these firms may adjust their overall pay scale only infrequently. There is currently debate about whether there is evidence in the data that wages of new hires are sticky. Pissarides (2007) and Haefke, Sonntag, and van Rens (2008), for example, find little empirical support for wage stickiness for new hires.

${ }^{22}$ The reason is that in existing matches the average wage rate is not allocative but rather splits the surplus of the match among the two parties. In particular, even when fixing the average hourly wage rate, this does not fix the hourly wage rate schedule. As part of an efficient bargaining agreement, the relevant section of marginal wages can be freely set in a state-contingent way even if average wage rates are fixed.

${ }^{23}$ See also Trigari (2006). Krause and Lubik (2007) find that wage stickiness is irrelevant for inflation dynamics. This rests on their assumption that there is only an extensive margin, in which case marginal costs indeed are little affected.
} 
makes hiring more responsive to a monetary easing. This means that the demanddriven increase in labour input is borne more by the number of employees rather than by hours worked. As a result, the average worker works fewer hours than in the absence of wage stickiness. This means that the marginal rate of substitution rises less strongly and also that the marginal product of labour falls less strongly. So, wage stickiness for new hires, through its effect on employment, makes marginal costs (and thus inflation) less responsive to a monetary easing.

Figure 2 illustrates the empirical implications of this. In the baseline setup, equation (13) implies that employment reacts only with a lag. With wage stickiness in new matches, employment reacts more strongly. This leads to a quicker fall in the response of hours, lowering the persistence of the responses of marginal cost and inflation. While future marginal costs and inflation thereby react less than in the absence of wage rigidity, quantitatively the differences are tiny, as Figure 2 illustrates. Complementing the results in this section, Section 7 assesses the case when the baseline is modified to allow for contemporaneous hiring, in which case employment is a jump variable and the initial response of hours worked per employee is thereby attenuated.

\subsection{Right-to-manage bargaining}

Section 4 highlighted that right-to-manage implies a close relationship between hours worked and wages. In this section, we allow for stickiness in these wages. In particular, if the wage of a worker has been bargained $i$ periods ago, he or she will work

$$
h_{t}\left(w_{t-i}^{*}\right)=\left(\alpha \frac{x_{t}}{w_{t-i}^{*}} \frac{p_{t}}{p_{t-i}}\right)^{\frac{1}{1-\alpha}}=h_{t-i}\left(w_{t-i}^{*}\right)\left(\alpha \frac{x_{t}}{x_{t-i}} \frac{p_{t}}{p_{t-i}}\right)^{\frac{1}{1-\alpha}}
$$

hours. Here, we let $w_{t-i}^{*}=\frac{w_{t-i}^{n, *}}{p_{t}}$ represent the real value of the nominal wage negotiated at time $t-i . \quad w_{t-i}^{n, *}$ is the nominal wage rate negotiated $i$ periods ago, which for some matches will continue to prevail today.

The asset value of a job clearly depends on the bargained wage. Adopting the viewpoint of an intermediate producer, we denote by $J_{t}\left(w_{t-j}^{*}\right)$ the asset value in period $t$ of a job with a wage that was bargained $i$ periods ago. Ex ante, the asset value of a new match for the firm can be written as

$$
J_{t}=\left(1-\xi_{w}^{n}\right) J_{t}\left(w_{t}^{*}\right)+\xi_{w}^{n} J_{t}\left(w_{t-1}\right)
$$

where $w_{t}$ is the average real value of all hourly wages. The asset value of a vacant job $V_{t}$ is still given by equation (15); i.e., the vacancy posting condition is not modified. 

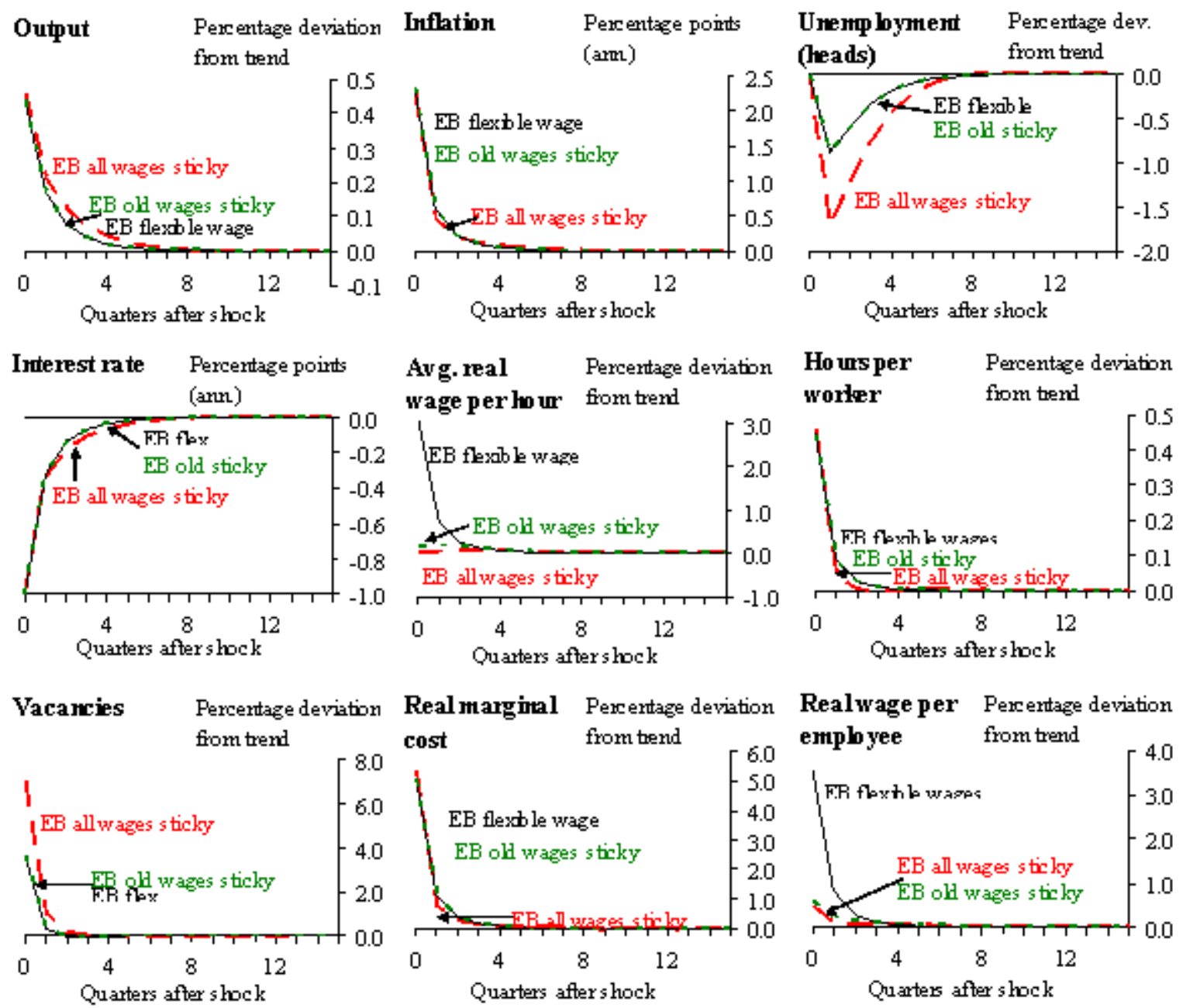

$$
\begin{aligned}
& \text { - - efficient bagaining all wages ane sticky, 占wo=chwF } 0.83 \\
& \text { - effrient bagaining flexble wages (baseline) } \\
& \text { - - effrient bagaining wages of exis ting matches sticky, 卣wo=0.83, 卣wrF } 0
\end{aligned}
$$

Figure 2: MONETARY EASING - EFfICIENT BARGAINING AND WAGE RIGIDITY OLD AND NEW HIRES. Shown are impulse responses to an unanticipated 100 bps reduction in the quarterly nominal interest rate in quarter 0 . All entries are in percentage deviations from steady state. Interest rates and inflation rates are reported in annualized terms. The black solid line marks the baseline response. A red dashed line marks the response when both wages of new hires and of old matches are sticky. The green dotted line shows the response when only wages of old hires are sticky. 
All the (re-)negotiating firm-worker couples face the same problem and therefore choose the same wage $w_{t}^{*}$ through the usual Nash bargaining procedure

$$
\max _{w_{t}^{*}}\left[\mathcal{W}_{t}\left(w_{t}^{*}\right)-U_{t}\right]^{\eta}\left[J_{t}\left(w_{t}^{*}\right)\right]^{1-\eta}
$$

where the worker's surplus, $\mathcal{W}_{t}\left(w_{t}^{*}\right)-U_{t}$, takes into account the fact that wages may not be renegotiated immediately. After some algebra, we obtain the wage equation for wages negotiated at time $t$

$$
\eta J\left(w_{t}^{*}\right) \Omega_{t}^{\prime}=(1-\eta)\left[\mathcal{W}_{t}\left(w_{t}^{*}\right)-U_{t}\right]
$$

with

$$
\Omega_{t}^{\prime}=\frac{1}{1-\alpha}\left[\frac{\chi h_{t}\left(w_{t}^{*}\right)^{1+\phi-\alpha}}{\alpha \lambda_{t} x_{t}} \frac{\mathrm{E}_{t} \sum_{i=0}^{\infty}\left(\beta(1-\rho) \xi_{w}^{o}\right)^{i}\left[\frac{x_{t+i}}{x_{t}} \frac{p_{t+i}}{p_{t}}\right]^{\frac{1+\phi}{1-\alpha}}}{\mathrm{E}_{t} \sum_{i=0}^{\infty}\left(\beta(1-\rho) \xi_{w}^{o}\right)^{i}\left[\frac{x_{t+i}}{x_{t}}\left(\frac{p_{t+1}}{p_{t}}\right)^{\alpha}\right]^{\frac{1}{1-\alpha}}}-\alpha\right]
$$

Figure 3 shows the response to a monetary easing in the right-to-manage model with flexible wages (which are similar to the efficient bargaining baseline) and the two alternatives with nominal wage rigidities. Two observations are in order. First and foremost, the combination of the right-to-manage bargaining with nominal wage stickiness produces much more rigid wages. These translate into a more reasonable response of inflation and into inflation persistence. In other words, the combination of sticky wages with 'right-to-manage' bargaining is able to generate a magnitude of the response of inflation to a monetary policy shock that is in line with the stylised facts. This follows directly from the fact that in right-to-manage bargaining, there is a direct cost channel from wages to marginal cost to inflation. Second, the responses are very similar for the two cases of wage rigidity. Whether wage rigidity affects only existing matches, or all matches, does not matter much for inflation dynamics; Christoffel and Kuester (2008) make a similar point.

\section{Real rigidities arising within the individual firm}

Following most of the existing literature, the baseline assumed that price-setting firms can buy labour goods, $y_{t}^{l}$, in a competitive factor market at cost $x_{t}$ per unit. They then transform this into a differentiated product. Due to this assumption, price-setting firms' marginal costs are independent of their own output level. In that setup only if 

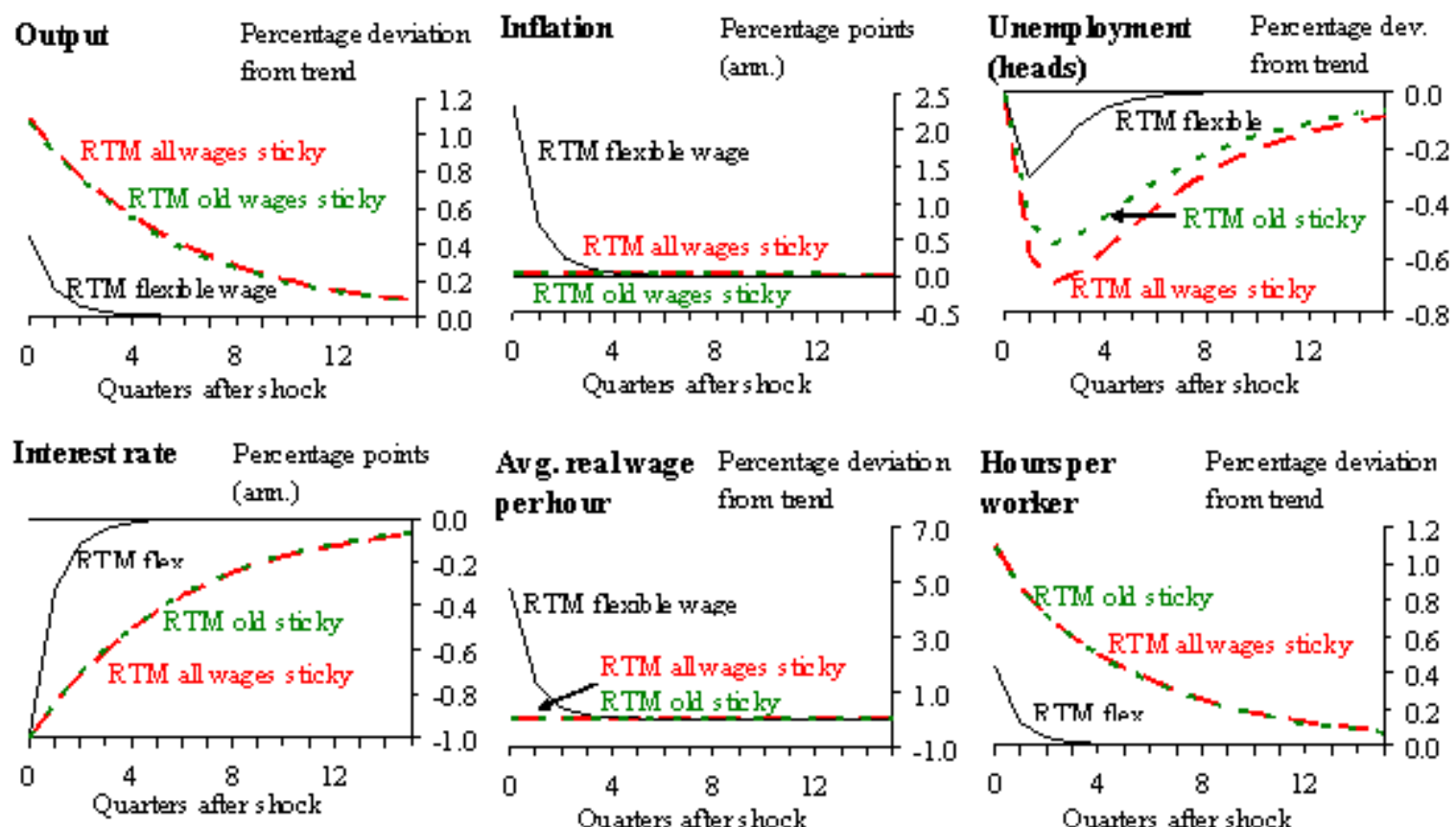

Avg.realwage Percentage deviation perhour from trend
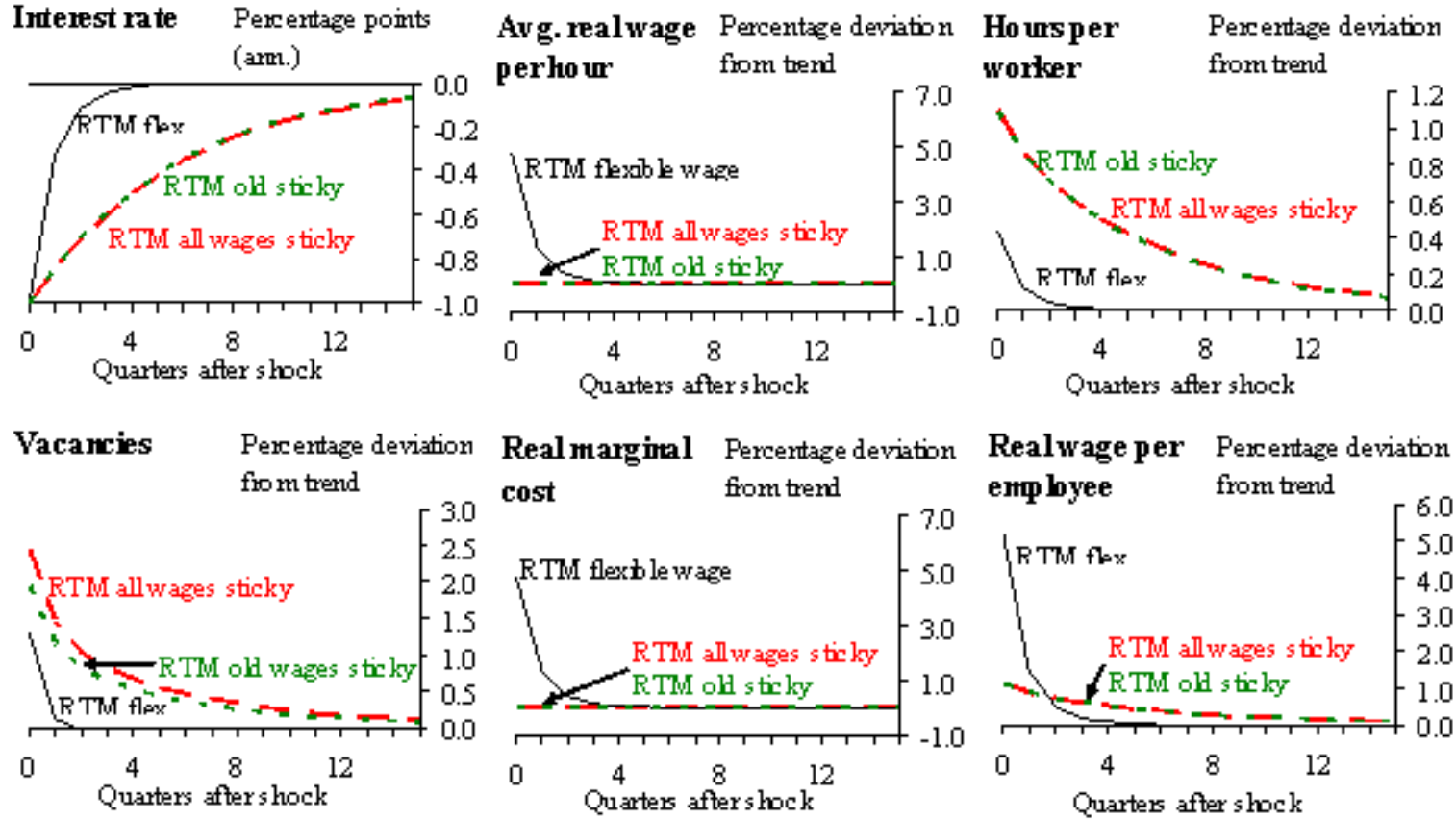
cost from trend $\quad 770$ employee fromtrend $\quad 6.0$
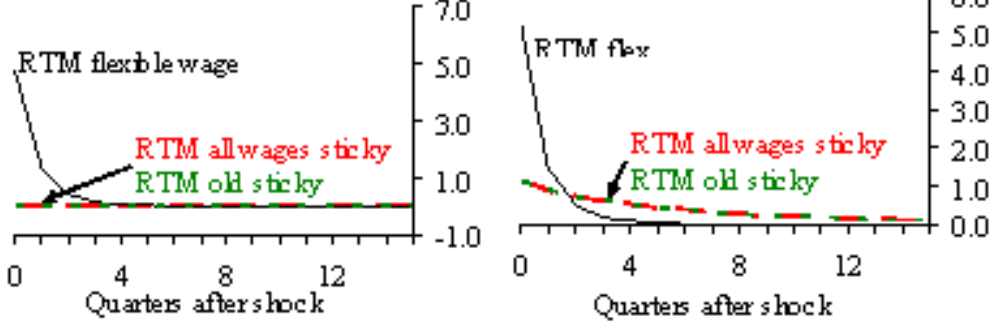

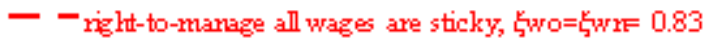

- riglt-to-manage flexable wages

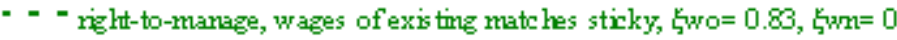

Figure 3: IMPUlSe RESPONSES TO A MONETARY EASING RIGHT-TO-MANAGE With WAGE RIGIDITY. Shown are impulse responses to an unanticipated 100 bps reduction in the quarterly nominal interest rate in quarter 0 . All entries are in percentage deviations from steady state. Interest rates and inflation rates are reported in annualized terms. The black solid line shows the response in the right-to-manage model in the absence of wage rigidity. The red dashed line shows the response when all wages are sticky. The green dotted line shows the case in which wage rigidity affects only existing matches. 
aggregate marginal costs are more rigid will inflation be more rigid. Following Kuester (2007), this section instead merges the intermediate labour good sector with the retail sector and emphasises real rigidities arising at the individual firm level over and above the real rigidities arising at the aggregate level. Related papers are Sveen and Weinke (2007) and Thomas (2008).

The presence of search and matching frictions in the labour market means that a worker in this economy temporarily constitutes a firm-specific factor of production to the firm at which he is employed. ${ }^{24}$ This, in turn, means that a firm's price setting has an effect not only on the demand that the firm faces but also on the wage demand of its worker and thus on the firm's own marginal costs.

As a consequence, for any given behaviour of aggregate marginal costs, firms are induced to adjust prices by less. The mechanism at work is the following. Consider an aggregate shock that, all else equal, would imply an increase in the marginal cost of all firms. A firm that can re-optimise its price passes part of the cost increase on to consumers. The increase in its price causes a fall in demand. This fall in demand will be the stronger the more price-elastic is demand; i.e., the larger is $\epsilon=\frac{1}{1-\mu_{p}}$. In turn hours worked at the firm fall (the more the production function exhibits decreasing returns to scale the more hours worked fall; i.e., the smaller is $\alpha$ ). So, in sum, the larger $\epsilon$ is and the smaller $\alpha$ is the more hours worked fall in response to a price increase. If workers have an increasing marginal disutility of work, i.e., $\phi>0$, this fall in hours worked leads to a reduction in the worker's marginal disutility of work. Therefore, at the time the firm decides what price it will set, it anticipates that the price increase will induce an effect that balances the original increase in marginal costs: workers take part of the original cost increase on themselves by accepting lower marginal wage rates. This implies that price-setting firms decide to move their prices by less for any given behaviour of aggregate marginal costs than in the baseline model, curbing the response of inflation to shocks relative to the benchmark model. ${ }^{25}$

This intuition is captured in the New Keynesian Phillips curve for the modified model

\footnotetext{
${ }^{24}$ In the intermediate labor sector of the baseline model, workers also constituted a temporarily firmspecific production factor. By assumption, however, this sector operated under perfect competition and flexible prices.

${ }^{25}$ It seems important to distinguish between real rigidities arising at the aggregate level and real rigidities arising at the individual firm level. For real rigidities arising at the aggregate level, as in Ball and Romer (1990), prices (and thus inflation) will respond the less to shocks the less (the aggregate component of) marginal cost responds to these shocks. For real rigidities arising at the individual firm level, prices will respond the less to shocks the more (the firm-specific component of) any firm's marginal cost rises with demand. For a further exposition, see also Woodford (2003, Chapter 3).
} 
economy:

$$
\widehat{\pi}_{t}=\beta(1-\rho) E_{t}\left\{\widehat{\pi}_{t+1}\right\}+\frac{1-\xi_{p}}{\xi_{p}}\left[1-\beta(1-\rho) \xi_{p}\right]\left\{\frac{1}{1+\frac{\epsilon}{\alpha}[(1-\alpha)+\phi]}\right\} \widehat{x}_{t} .
$$

With respect to the baseline New Keynesian Phillips curve, equation (9), there is an additional term dampening the pass-through of marginal cost on inflation (underlined). As the discussion above suggested, the more price-elastic demand is (the larger $\epsilon$ is), the more curved the marginal disutility of labour is (the larger $\phi$ ) and the faster the returns to hours per employee decrease at the firm level (the smaller $\alpha$ ), the less will firms adjust prices to aggregate shocks, and therefore the weaker will be the response of inflation to its aggregate driving forces.

Figure 4 compares the impulse response to a monetary easing in the baseline model to the model with firm-specific labour. The additional factor in the New Keynesian Phillips curve (33) is equal to $\left\{\frac{1}{1+\frac{\epsilon}{\alpha}[(1-\alpha)+\phi]}\right\}=0.009$. As a result, inflation reacts considerably less to the monetary shock when allowing for firm-specific labour, bringing the response more in line with the stylised facts. In turn, this implies that the monetary easing provides more stimulus, which translates into a response of output that is larger than in the baseline.

\section{Contemporaneous hiring}

In the variants of the search model discussed above there was a one-period lag before a worker hired in $t$ takes on the job. In light of the empiricial evidence on short-term fluctuations in employment, it is useful to look at a variant allowing for contemporaneous hiring. ${ }^{26}$ This section follows Ravenna and Walsh (2008) and assumes the following timing. As before, at the beginning of each period some firms and workers randomly separate. Firms that are not matched with a worker can post vacancies. Contrary to the case in previous sections however, the successful matches become productive in the same period. So employment evolves according to $n_{t}=(1-\rho) n_{t-1}+m_{t}$. This timing assumption implies the following flow values for the value of a job to the firm and the value of a vacancy

\footnotetext{
${ }^{26}$ Data for the U.S. show that more than $60 \%$ of unemployment spells take less than 14 weeks; see "Labor Force Statistics from the Current Population Survey." For the euro area the proportion of short-term unemployed (up to a 2-month unemployment spell) in total employment was around $15 \%$ in the period between 2005q1 and 2008q2, according to the OECD Labor Force Survey. Including spells of up to 5 months implies a proportion of roughly $30 \%$ of short-term unemployment in total unemployment.
} 

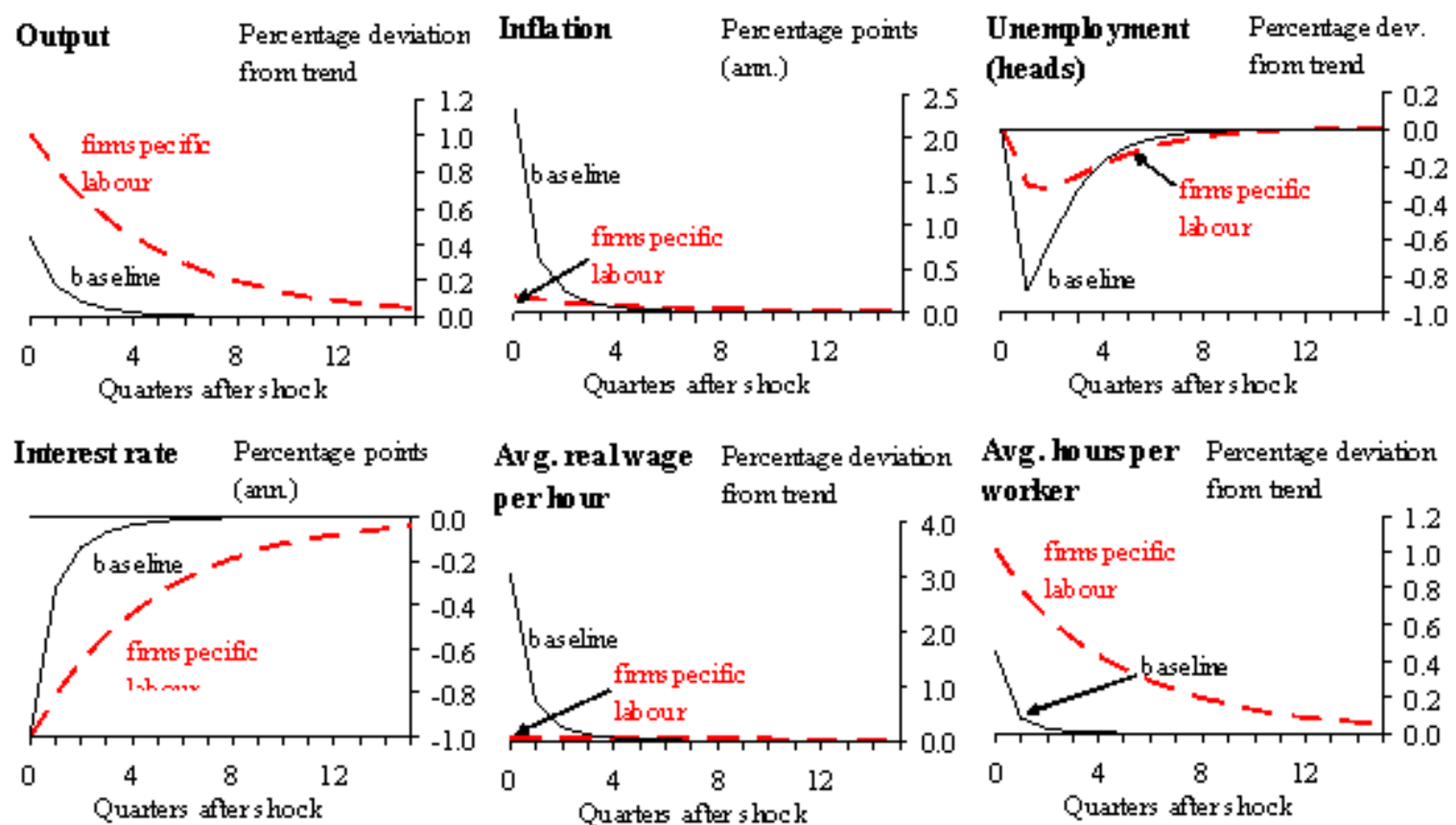

Avg.realwage Percentage deviation perbur fromtrend

Avg. hous per Percentze deviation worker from trend
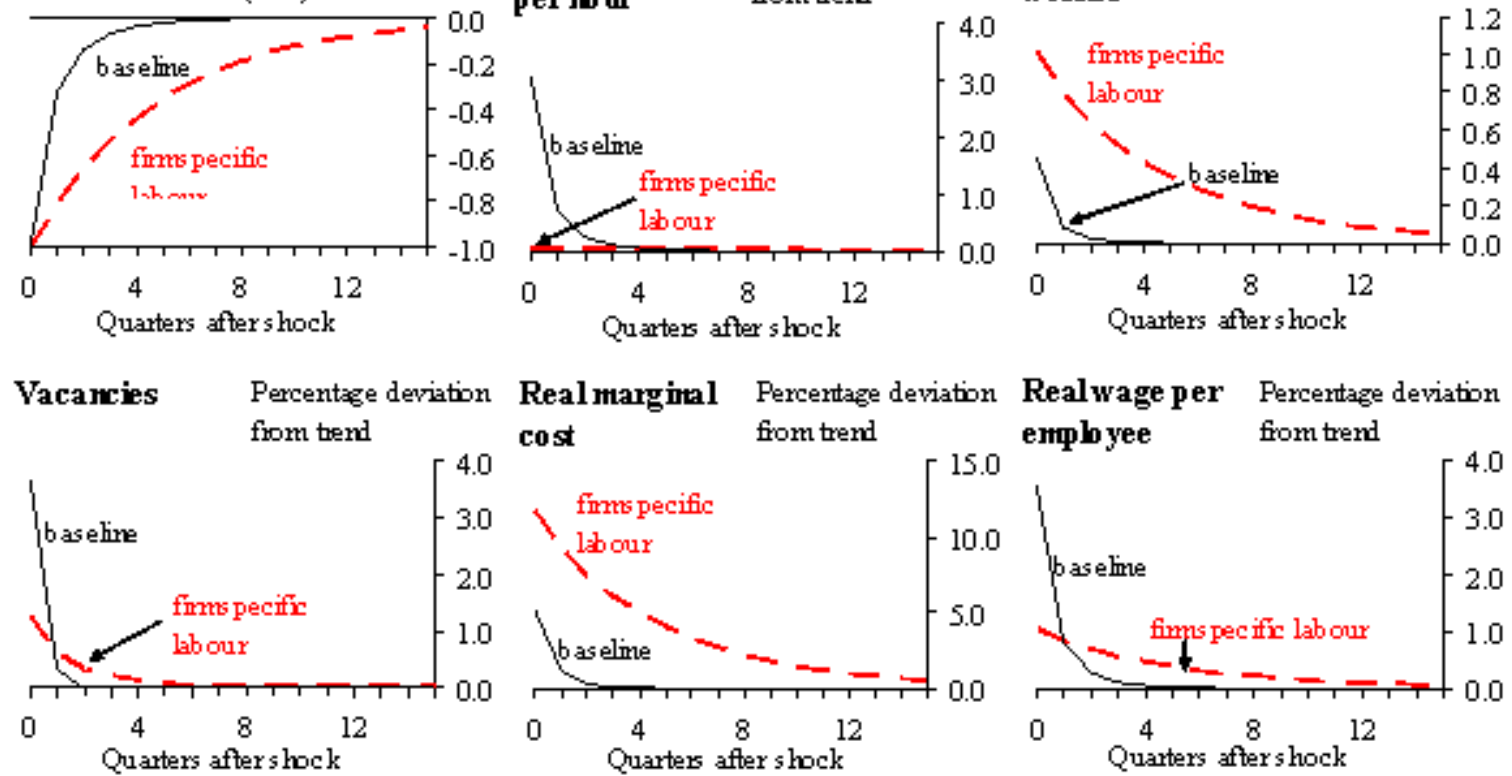

Real marginal Percentage deviation cost from trend

Realwage per Percentage deviation enplo yee from trend
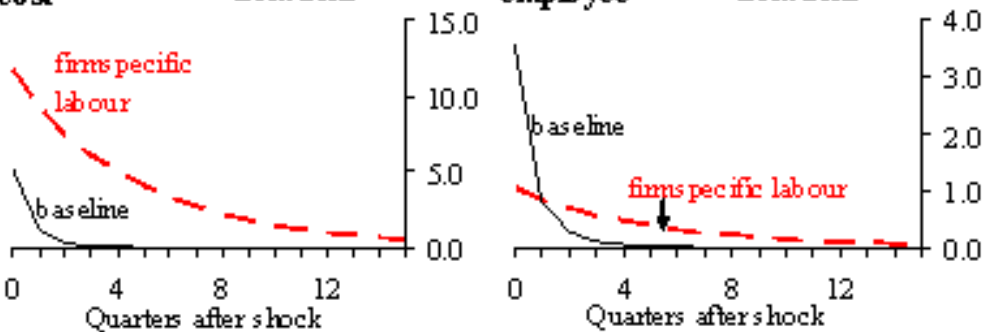

Figure 4: Impulse Responses to A MONETARY EASING - Firm-SPECIfiC LAbour VS BASELINE. Shown are impulse responses to an unanticipated 100 bps reduction in the quarterly nominal interest rate in quarter 0 . All entries are in percentage deviations from steady state. Interest rates and inflation rates are reported in annualized terms. The black solid line shows the response in the efficient bargaining baseline, which separates price setting and wage setting into two different sectors. The red dashed line shows the response of the economy when these two sectors are merged. 


$$
\begin{aligned}
J_{t} & =y_{t}^{l} x_{t}-h_{t} w_{t}+\mathrm{E}_{t}\left\{\beta_{t, t+1}(1-\rho) J_{t+1}\right\} \\
V_{t} & =-\kappa+q_{t} J_{t}+\mathrm{E}_{t}\left\{\beta_{t, t+1}\left(1-q_{t}\right) V_{t+1}\right\}
\end{aligned}
$$

The flow value of being employed, $W_{t}$, and the flow value of being unemployed, $U_{t}$, are defined with respect to the end of the period after the formation of the current period matches.

$$
\begin{gathered}
W_{t}=h_{t} w_{t}-\frac{\chi}{\lambda_{t}} \frac{h_{t}^{1+\phi}}{1+\phi}+\mathrm{E}_{t}\left\{\beta_{t, t+1}\left[\left(1-\rho+\rho s_{t+1}\right) W_{t+1}+\rho\left(1-s_{t+1}\right) U_{t+1}\right]\right\} \\
U_{t}=b+\mathrm{E}_{t}\left\{\beta_{t, t+1}\left[s_{t+1} W_{t+1}+\left(1-s_{t+1}\right) U_{t+1}\right]\right\} .
\end{gathered}
$$

Figure 5 shows the response to the monetary easing. The introduction of contemporaneous hiring has a direct impact on marginal costs. As matches become productive within the period, labour adjustment moves from the intensive to the extensive margin. As a result the reaction of employment is considerably more pronounced and the reaction of hours per worker is lower than in the baseline. The peak response of unemployment occurs in the first period and exceeds the peak response in the baseline by a factor of two. The strong response of employment implies a lower reaction of hours and a slightly lower wage response. The overall impact on the inflation response is small nevertheless.

\section{Variants of the vacancy posting process}

How vacancy creation moves over the business cycle is essential for determining the response of the intensive versus the extensive margin of labour adjustment. As discussed in section 3.3, this in turn has a bearing on the response of marginal wages, marginal cost and inflation over the business cycle. This section studies the implications of two modifications of the vacancy posting process that have been introduced in the RBC literature on frictional unemployment with the aim of helping the Mortensen and Pissarides model reproduce labour market stylised facts. The first modification, following Yashiv (2006), draws on the intuition that it is easier to incorporate a worker into a company when employment is high already. The second modification, following Fujita and Ramey (2007), eases the free-entry condition. 

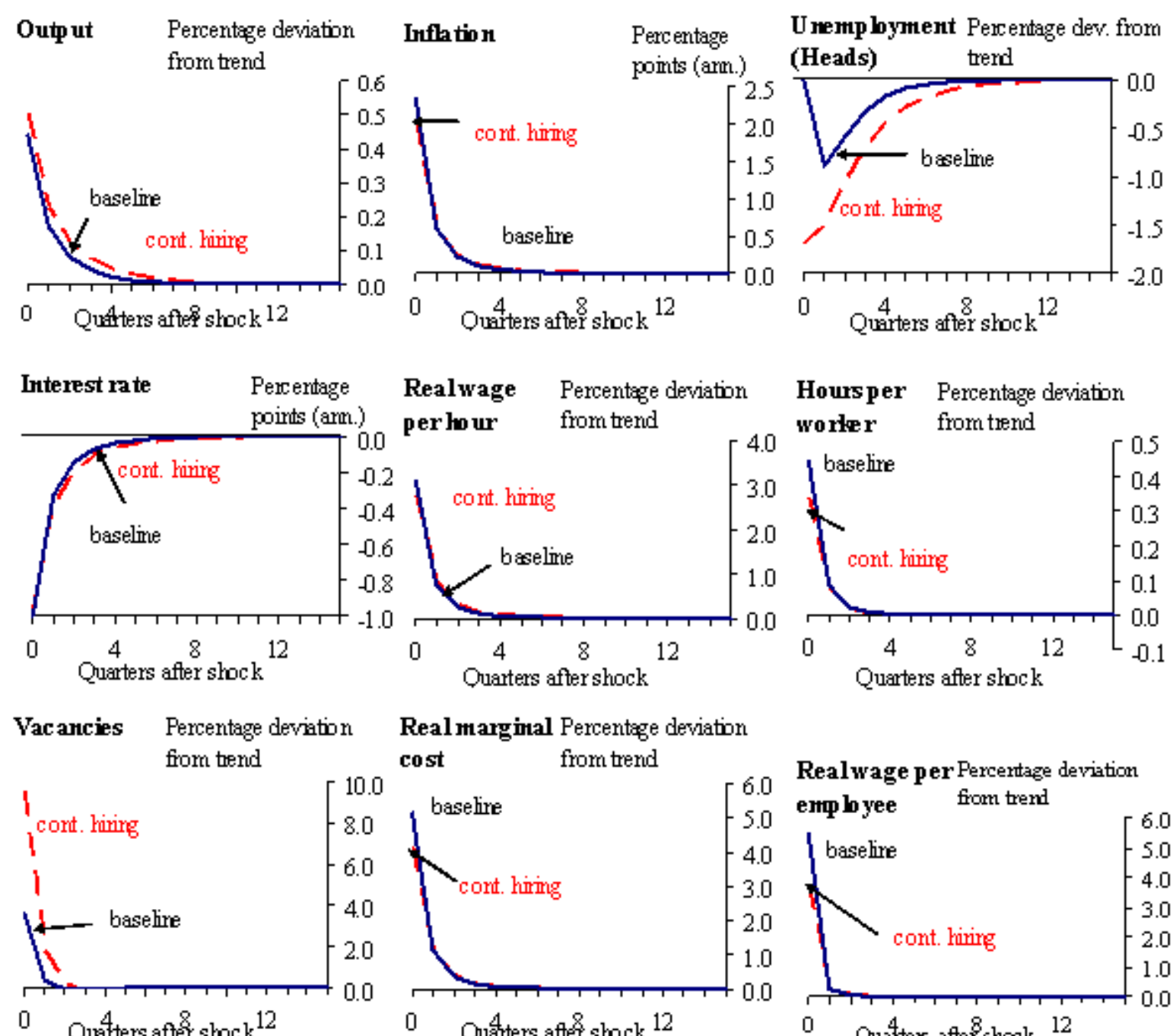

Real marginal Percentage deviation cost from trend
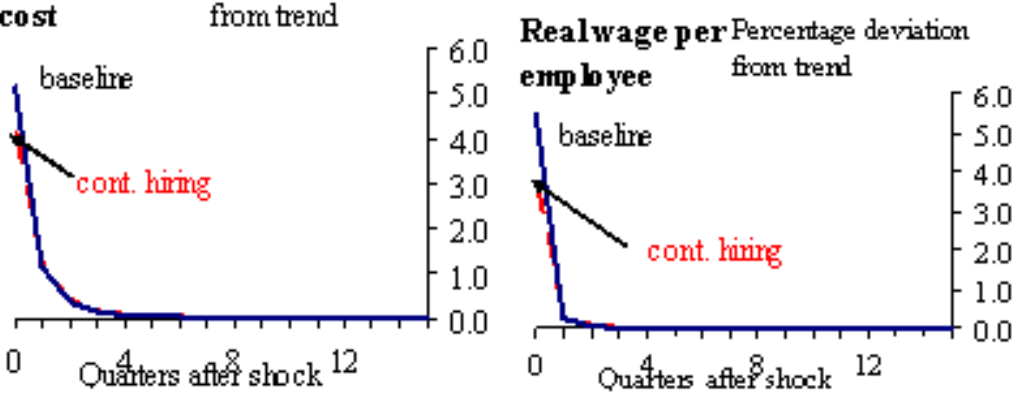

Figure 5: Impulse Responses tO A MONETARY EASIng - Contemporaneous HIRING VS BASELINE. Shown are impulse responses to an unanticipated 100 bps reduction in the quarterly nominal interest rate in quarter 0 . All entries are in percentage deviations from steady state. Interest rates and inflation rates are reported in annualized terms. The black solid line shows the response in the efficient bargaining baselines. The red dashed line shows the response of the economy when we allow for contemporaneous hiring. 


\subsection{Employment adjustment costs convex in the hiring rate}

In the first variant of the model, we drop the assumption of a fixed recurrent vacancy posting cost. Instead, we follow Gertler and Trigari (2006) and assume that total hiring costs are a quadratic function of the hiring rate. The idea is that hiring costs not only increase with the number of new hires but also with the ratio of new hires to existing jobs, ${ }^{27}$

$$
k_{t}^{v} v_{t}=\psi\left(\frac{m_{t}}{n_{t}}\right)^{2} n_{t}
$$

where we assume that the total hiring cost is shared equally among all firms that posted a vacancy. Transforming (38), the cost per hiring, $k_{t}^{v} / q_{t}=\psi \frac{m_{t}}{n_{t}}$, is proportional to the hiring rate $\frac{m_{t}}{n_{t}}$. This is in contrast to the baseline where the cost per hire typically increases with $n_{t}$ due to the congestion effect associated with the search and matching process. All else equal, this will lead to greater variation in employment and thus less variation in marginal costs and inflation. Using the free-entry condition $V_{t}=0$ and substituting for $k_{t}^{v}$, equations (22), (23) and (24) are left unmodified but for the substitution of $\kappa / q_{t}$ by $\psi m_{t} / n_{t}$, so that the dynamics of the job creation condition will be determined by the hiring rate instead of the probability of filling a vacancy.

Figure 6 shows that hiring reacts more strongly to shocks relative to the baseline, so future real marginal costs react less strongly, reducing the effect of the shock on inflation. Quantitatively, however, in our calibration the effect is tiny.

\subsection{Vacancy costs as sunk costs}

An alternative to convex costs is a sunk cost, as in Fujita and Ramey (2007). In this case, firms pay a sunk cost only once when they post a new vacancy. Every period, all the firms that have neither a worker nor a vacancy draw their sunk cost, $K$, out of a distribution, $F(K)$. Among these, all the firms endowed with a sunk cost lower than

$$
\overline{S C}_{t}=\mathrm{E}_{t}\left\{\beta_{t, t+1}\left[q_{t} J_{t+1}+\left(1-q_{t}\right) \overline{S C}_{t+1}\right]\right\}
$$

will post a vacancy.

\footnotetext{
${ }^{27}$ The rationale for this way of modelling is in understanding a match as one job in large, multiworker firms. The reason why costs per hiring decrease with the labour force is simply that more employment eases the integration of new hires.
} 

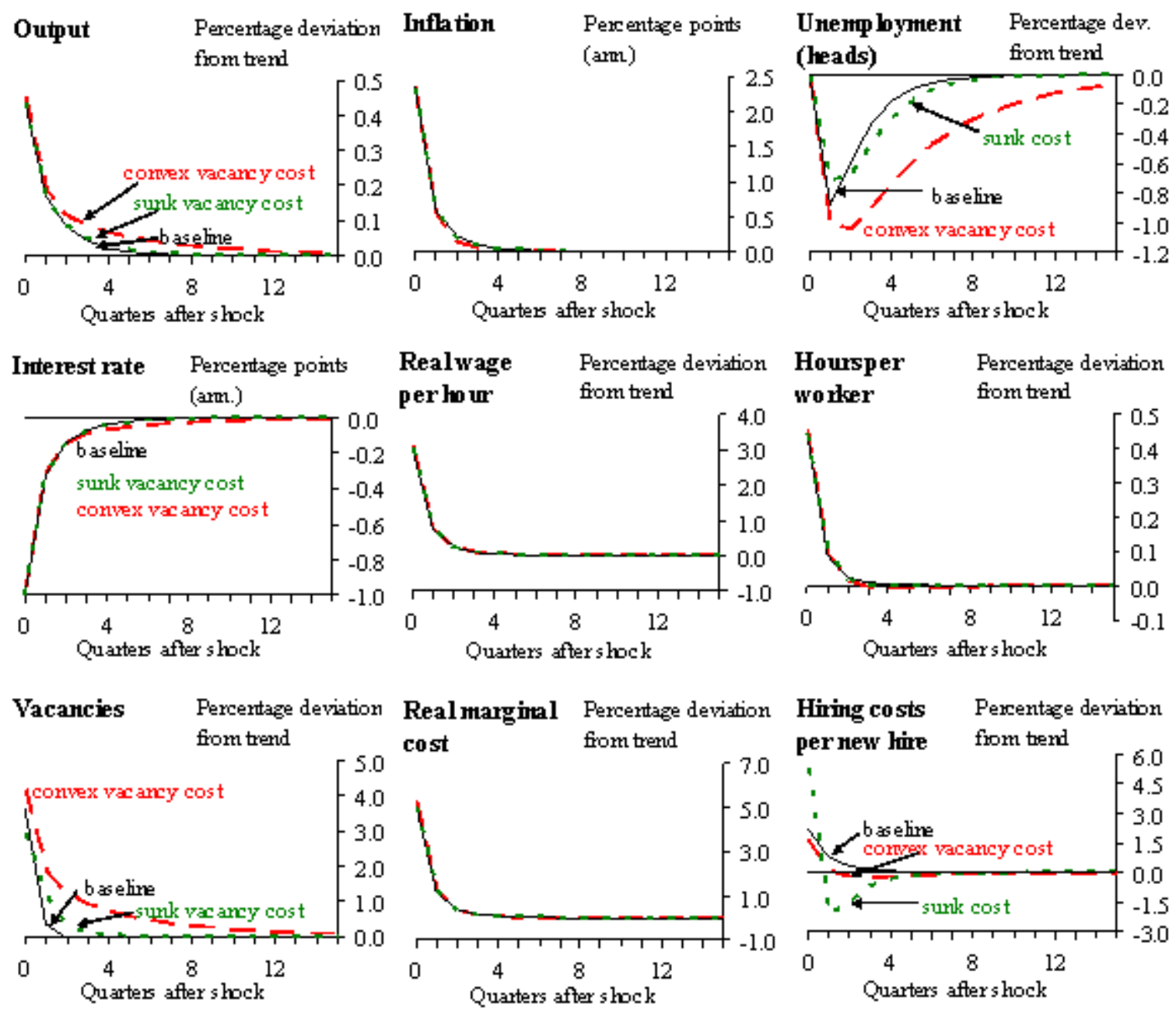

$$
\begin{aligned}
& \text { - - corvex vacancy pos ting cost } \\
& \text { - baeline } \\
& \text { - - surk vacancy cost }
\end{aligned}
$$

Figure 6: IMPUlSE RESPONSES TO A MONETARY EASING WHEN ALLOWING FOR DIFFERENT VACANCY POSTING COSTS THAN IN THE BASELINE AND DIFFERENT VACANCY CREATION TECHNOLOGY. Shown are impulse responses to an unanticipated $100 \mathrm{bps}$ reduction in the quarterly nominal interest rate in quarter 0 . All entries are in percentage deviations from steady state. Interest rates and inflation rates are reported in annualized terms. The solid line shows the response in the baseline, which features constant costs per vacancy over the cycle, and in which these costs keep a vacancy open for exactly one period. The red dashed line represents the response in the variant with adjustment costs convex in the hiring rate. The green dotted line is the response in the variant where vacany costs are sunk. 
Denoting the newly posted vacancies by $v_{t}^{n}$, we obtain that

$$
v_{t}^{n}=F\left(\overline{S C}_{t}\right)
$$

and the law of motion of vacancies is:

$$
v_{t}=\left(1-q_{t-1}\right) v_{t-1}+v_{t}^{n}
$$

Let us assume that the cumulative distribution is a linear function of the sunk cost

$$
F(K)=\varkappa(K-\bar{k}), \varkappa>0
$$

where $\bar{k} \geq 0$ is the lowest sunk cost in the distribution while $\varkappa$ is a slope parameter. Of course, the lower (respectively higher) is $\bar{k}$ (respectively $\varkappa$ ), the higher is the number of new vacancies and the more volatile is employment. Finally, total vacancy posting costs are given by:

$$
\varkappa \int_{\bar{k}}^{V_{t}} K d K=\varkappa\left(\frac{\overline{S C}_{t}^{2}-\bar{k}^{2}}{2}\right)
$$

Note that in this variant, no equation of the baseline model is modified except for that governing vacancy posting costs. The corresponding wage equation is obtained by substituting (14), (16) and (17) into (21) and cannot be further simplified. As illustrated by Figure 6 the addition of sunk costs clearly increases vacancy persistence (since vacancies are now a stock variable rather than a flow variable) but, again, the quantitative effects on the dynamic response of inflation to the shock are weak.

\section{On-the-job search}

In the baseline only unemployed workers can search, with the result that only they enter the matching function and can be matched up with vacancies. But, in reality, currently employed workers spend at least some of their time looking around for alternative job opportunities. The result of this is that job-to-job movements form a large part of all job destruction and creation and are, thus, potentially important for marginal costs over the cycle. ${ }^{28}$

Following Krause and Lubik (2006) and van Zandweghe (2009), we assume that jobs

\footnotetext{
${ }^{28}$ Akerlof et al. (1988) and Gomes (2008) suggest that job-to-job flows account for around $50 \%$ of all job separations in the United States and the United Kingdom, respectively. However, Contini and Revelli (1997) suggest that the proportion is smaller than this in euro area countries.
} 
come in two types: 'good' jobs (that pay higher wages) and 'bad' jobs (that pay lower wages). Aggregate output is produced using workers employed in both types of jobs. The presence of these two types of jobs creates an incentive for workers employed in bad jobs to search for good jobs. So, good firms are able to recruit from a pool of workers that includes both those unemployed workers who are searching for good jobs, $u_{g, t}$, and those currently employed in bad jobs, $e_{t}=\zeta_{t} n_{b, t}$, where $\zeta_{t}$ is the search intensity of employed workers and $n_{b, t}$ is employment in the bad sector. Given this, the relevant measure of labour market tightness for the 'good' sector will be $\tilde{\theta}_{t}=\frac{v_{t}}{u_{g, t}+e_{t}}$, where $u_{g, t}$ is unemployment of good sector workers. This measure of market tightness will likely be less volatile than the measure in the baseline model without search on-the-job, which was given by $\theta_{t}=\frac{v_{t}}{u_{t}}$. The reason is that job-to-job flows, $e_{t}$, will be procyclical. In a boom, more new vacancies will be posted than if there were no on-the-job search; since employment in the 'bad' sector is procyclical, the number of searching workers will also be procyclical, increasing the likelihood of filling a vacancy in a boom relative to the model with no on-the-job search. The first-order condition for employed search intensity will be given by:

$$
\begin{aligned}
\tau \gamma \zeta_{t}^{\tau-1}=\quad & \frac{\eta}{1-\eta}(1-\rho) \sigma_{m, g}\left(\frac{v_{g, t}}{u_{g, t}+e_{t}}\right)^{1-\vartheta} \\
& \cdot\left(\frac{\kappa_{g}}{\sigma_{m, g}}\left(\frac{v_{g, t}}{u_{g, t}+e_{t}}\right)^{\vartheta}-\frac{\kappa_{b}}{\sigma_{m, b}}\left(\frac{v_{b, t}}{u_{b, t}}\right)^{\vartheta}\right)
\end{aligned}
$$

where $\zeta_{t}^{\tau}$ is the cost of searching with intensity $\zeta_{t}$. As can be seen, as more vacancies are posted, employed workers increase their search intensity, which will lower expected hiring costs and increase the incentive to post vacancies even further. That is, the rising search activity of the employed in a boom forms an additional resource in the matching function that helps to keep hiring costs more stable. The model predicts that job-to-job flows rise in booms, in line with the data.

In the model with on-the-job search (and in the baseline model), the New Keynesian Phillips curve will continue to be given by (9). Given that final output is assumed to be a Cobb-Douglas function of output in each of the two sectors, real marginal cost will be given by:

$$
x_{t}=\left(\frac{x_{g, t}}{1-\omega}\right)^{1-\omega}\left(\frac{x_{b, t}}{\omega}\right)^{\omega}
$$

where $\omega$ denotes the share of the output of 'bad' jobs in final output. With efficient bargaining over hours, real marginal cost in each sector will again be equal to the 
marginal rate of substitution divided by the marginal product of labour in that sector:

$$
x_{g, t}=\frac{\chi}{\lambda_{t}} \frac{h_{g, t}^{1+\phi}}{\alpha y_{g, t}^{l}}
$$

and

$$
x_{b, t}=\frac{\chi}{\lambda_{t}} \frac{h_{b, t}^{1+\phi}}{\alpha y_{b, t}^{l}}
$$

So the response of real marginal cost to demand shocks will depend upon the response of hours in each sector to such shocks. On-the-job search leads to a reduced response in hiring costs in response to shocks; as this affects the extensive margin, this will reduce the response of future real marginal cost to shocks and, thus presumably, the response of inflation.

Despite this, however, Figure 7 shows that even with on-the-job search, the response of inflation is only slightly smaller than the inflation response in the baseline model. In turn, this is because of the large and immediate $6 \%$ rise in real marginal cost in response to this shock, offset only slightly by the lower response of real marginal cost in future periods relative to the baseline.

\section{Endogenous job destruction}

In much of the literature on frictional labour markets job separation is treated as an exogenous process, for several reasons: it makes the model easier to solve; it makes the model easier to calibrate; and it implies a robust negative correlation between unemployment and vacancies, whereas models that endogenise separation often have problems replicating the Beveridge curve. However, the separation rate rises in recessions. $^{29}$ Therefore, in this section we consider a version of the baseline model with endogenous separation. This imposes an additional first-order condition related to the separation margin and thus further restricts the model's predicted dynamics.

As in Mortensen and Pissarides (1994), we endogenise separation by assuming that each match has an idiosyncratic productivity component that is uncorrelated with aggregate productivity. Thus, the income produced by a match is given by $x_{t} z_{i t} h_{i t}^{\alpha}$, where $z_{i t}$ is the match-specific productivity component and the rest of the notation follows that in

\footnotetext{
${ }^{29}$ Sources of evidence for countercyclical separation in Europe include Burda and Wyplosz (1994). For the U.S., see Fujita and Ramey (2008). Shimer (2005) and Hall (2005) illustrate that this countercyclicality may be less pronounced than was previously believed.
} 


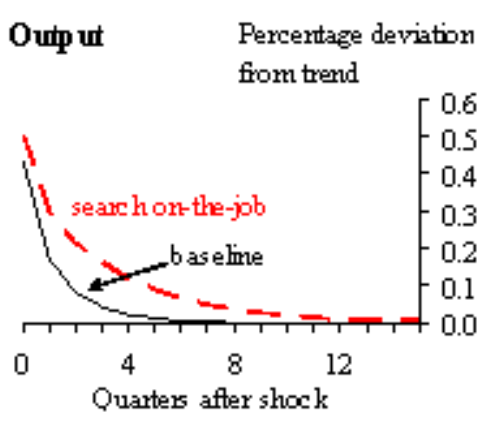

Interest rate Percentage points (arm)
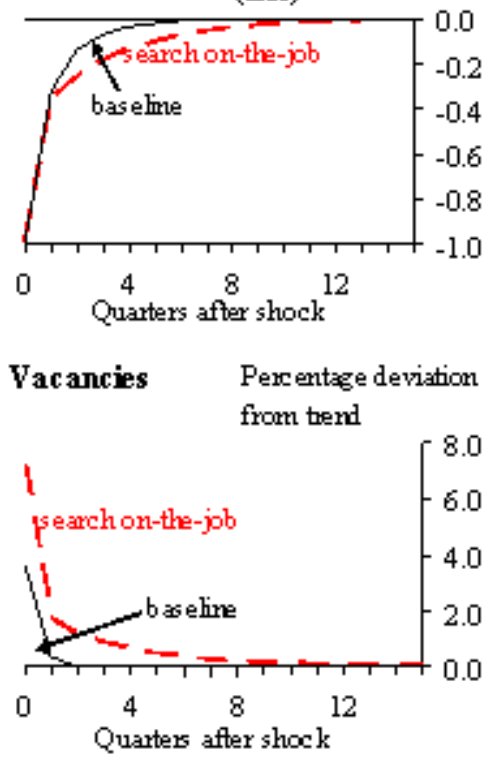

Percertage poirts

(arm.)

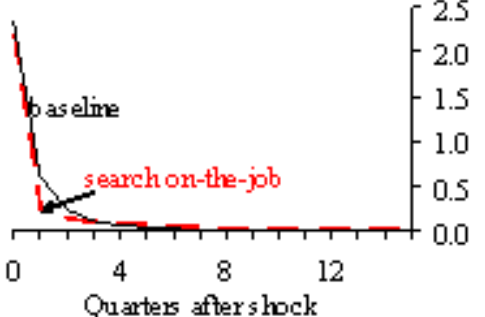

Realwage Percentage deviation perhour from thend

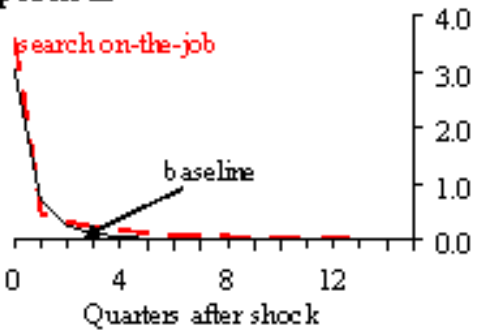

Real marginal cost
Percentage deviation from thend
Unemp loyment Percentage dev (heads) from trend

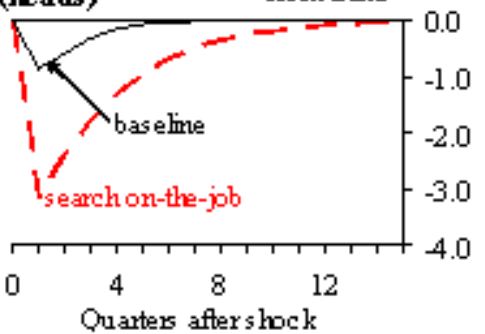

Ho urs per Percentage deviation worker from trend

U nemp byment Percentage dev.

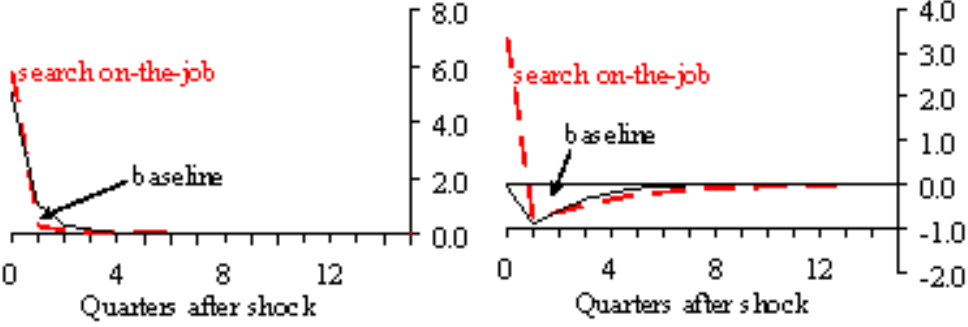

vartes after shock

- search orthe-job

baseline

Figure 7: IMPUlse RESPONSES TO A MONETARY EASING WHEN ALlOWING FOR SEARCH ON-THE-JOB. Shown are impulse responses to an unanticipated 100 bps reduction in the quarterly nominal interest rate in quarter 0 . All entries are in percentage deviations from steady state. Interest rates and inflation rates are reported in annualized terms. The black solid line shows the response in the baseline, which features homogeneous jobs, and in which workers are recruited only out of the unemployment pool. The red dashed line shows the response when allowing for search on-the-job. 
Section 2. We will assume $z_{i t}$ is normally distributed with a cumulative distribution $F$, with mean 1 and standard deviation $\sigma_{z}$. This distribution will allow us to nest the exogenous search model as a special case of our endogenous search model associated with $\sigma_{z} \longrightarrow 00^{30}$ We will call the reservation productivity at which separation occurs $\underline{z}_{t}$.

Following den Haan, Ramey, and Watson (2000), we assume that $z_{i t}$ is iid. That is, $z_{i t}$ is uncorrelated with the aggregate shock $x_{t}$, it is uncorrelated across individual matches $i$, and most important, it is uncorrelated over time. For continuity with the rest of the paper, we still include an exogenous separation component: at the end of each period, existing matches separate for exogenous reasons with probability $\rho^{x}$. Allowing for productivity shocks with distribution $F$ in all periods, and reservation productivity $\underline{z}_{t}$, the employment dynamics are:

$$
n_{t}=\left(1-F\left(\underline{z}_{t}\right)\right)\left[\left(1-\rho^{x}\right) n_{t-1}+m_{t-1}\right]
$$

The fraction of jobs surviving between periods $t-1$ and $t$ is therefore $1-\rho_{t} \equiv$ $\left(1-F\left(\underline{z}_{t}\right)\right)\left(1-\rho^{x}\right)$. The total number of worker-firm pairs that meet at the end of $t-1$ is $m_{t-1}=\sigma_{m} v_{t-1}^{\vartheta} u_{t-1}^{1-\vartheta}$, where $u_{t-1}=1-n_{t-1}$ but the number that actually enter into production at the start of $t$ is only $\left(1-F\left(\underline{z}_{t}\right)\right) m_{t-1}$.

The rest of the model has the structure spelled out in Section 2. In particular, we assume efficient bargaining, as in Section 2.4, which now implies that both wages and hours will depend on the match-specific productivity shock $z_{i t}$. Thus in the analogue to equation (14), a matched firm's value function is a function of the shock, $J_{t}\left(z_{i t}\right)$, and its flow of revenues is $x_{t} z_{i t} h_{t}\left(z_{i t}\right)^{\alpha}-w_{t}\left(z_{i t}\right) h_{t}\left(z_{i t}\right)$. A matched worker's value function $W_{t}\left(z_{i t}\right)$ also depends on the shock; the worker's flow payoffs are $w_{t}\left(z_{i t}\right) h_{t}\left(z_{i t}\right)-$ $\lambda_{t}^{-1} \frac{\chi}{1+\phi} h_{t}\left(z_{i t}\right)^{1+\phi}$. On the right-hand side of all the Bellman equations there will therefore be expectations of future values with respect to $z_{i t+1}$.

Efficient bargaining over hours gives a first-order condition that is equivalent to (20), except that it also takes into account the idiosyncratic productivity shock:

$$
h_{t}(z)=\left(\alpha x_{t} \lambda_{t} / \chi\right)^{\frac{1}{1+\phi-\alpha}} z^{\frac{1}{1+\phi-\alpha}} \equiv H_{t} z^{\frac{1}{1+\phi-\alpha}}
$$

Thus hours are proportional to $z^{\frac{1}{1+\phi-\alpha}}$ with the time-varying factor of proportionality $H_{t}$, which will help us aggregate hours and wages. This allows us to integrate

\footnotetext{
${ }^{30}$ We will choose parameters such that continuation is optimal for $z=1$, implying a reservation productivity strictly less than one. In the limit as $\sigma_{z} \longrightarrow 0$, the fraction of separations occurring endogenously goes to zero and the mean of $z$ for continuing matches goes to one. Therefore in this limit the additional first-order condition serves only to define the separation threshold, which has no effect on the remaining equations of the model.
} 
across productivity to express all quantities in aggregate terms. After some algebraic manipulation, the job creation Euler equation analogous to (24) becomes

$$
\frac{\kappa}{q_{t}}=E_{t}\left\{\beta_{t, t+1}\left[\begin{array}{l}
\frac{(1-\eta)(1+\phi-\alpha)}{1+\phi} \frac{x_{t+1} c_{t+1}}{n_{t+1}} \\
-\left(1-F\left(\underline{z}_{t+1}\right)\right)\left(\eta \kappa \theta_{t+1}+(1-\eta) b\right)+\left(1-\rho_{t+1}\right) \frac{\kappa}{q_{t+1}}
\end{array}\right]\right\}
$$

The reservation productivity $\underline{z}_{t}$ satisfies the job destruction equation $J_{t}\left(\underline{z}_{t}\right)=0$. Eliminating the wage and expected future values from the Bellman equation for $J$, the job destruction equation can be written as

$$
\frac{(1-\eta)(1+\phi-\alpha)}{1+\phi} x_{t} H_{t}^{\alpha} \underline{z}_{t}^{\frac{1+\phi}{1+\phi-\alpha}}-\eta \kappa \theta_{t}-(1-\eta) b+\left(1-\rho^{x}\right) \frac{\kappa}{q_{t}}=0
$$

Calibrating this version of the model requires us to determine what fraction of separations are endogenous. For the U.S., Davis and Haltiwanger roughly calculated the fraction of endogenous separations in U.S. data by comparing firm-level job destruction (which they argue should reflect changes in firms' labour demand, and therefore map into the model's endogenous component) with total worker separation flows (which are larger and should include worker-initiated changes in employment status, which they map into the model's exogenous component). They find that the endogenous component is roughly $40 \%$ of the total, which - absent evidence for the euro area - is the number we will use here. Then for any standard deviation $\sigma_{z}$ of the idiosyncratic shock, we can calculate $\underline{z}=F^{-1}(0.4 \cdot 0.06)$, assuming $6 \%$ total separation flows as before, and from $\underline{z}$ we can calculate all the integrals over $z$ that appear in the equations.

Other parameters can be backed out as before: $\sigma_{m}$ can be deduced from observed job flows, and $\chi$ can be chosen so that (46) is satisfied. Finally, we can choose $\kappa$ and $b$ for consistency with the job creation and job destruction equations, (47) and (48). For a given $\sigma_{z}$, this makes the replacement ratio endogenous, so this calibration strategy will not automatically generate the same replacement rate used in previous sections of the paper. Therefore, we have simulated the model for a range of values $\sigma_{z}$, looking for a parameterisation that implies the same replacement ratio assumed in the baseline model. When we set the standard deviation of the idiosyncratic shock to $\sigma_{z}=0.4$, we obtain a $65 \%$ replacement ratio, as in the baseline model.

For this parameterisation, Fig. 8 shows the impulse responses for endogenous separation together with those of the exogenous separation model that has the same replacement ratio $(65 \%)$. The monetary stimulus primarily goes into wages. The overall stimulative effect of the money shock is relatively small. ${ }^{31}$ As the figure shows, hours

\footnotetext{
31 Interestingly, there are various parameter regions implying major qualitative changes in the
} 
per worker and vacancies both rise, but separation and unemployment increase, too, for this calibration. While inflation and most other aggregate variables behave similarly in the two cases, the introduction of endogenous separation thus leads to counterfactual implications for unemployment. We thus confirm a previous finding in the literature, e.g., Krause and Lubik (2007), that even when endogenising separation has little impact on quantities outside of the labour market, it can be very hard to force all the margins of labour market adjustment to co-move realistically.

impulse responses, including regions of indeterminacy. For example, setting $\sigma_{z}=0.1$, which leads to a replacement ratio of $84 \%$, we find that a monetary stimulus causes a large fall in the separation rate. Under these parameters, unemployment is more volatile (and responds in the right direction) and wages and inflation are much smoother. Thus, while the parameterisation with $\sigma_{z}=0.4$ fails to improve the model's inflation predictions, the effects of endogenous separation differ (and improve relative to the data) at $\sigma_{z}=0.1$. 

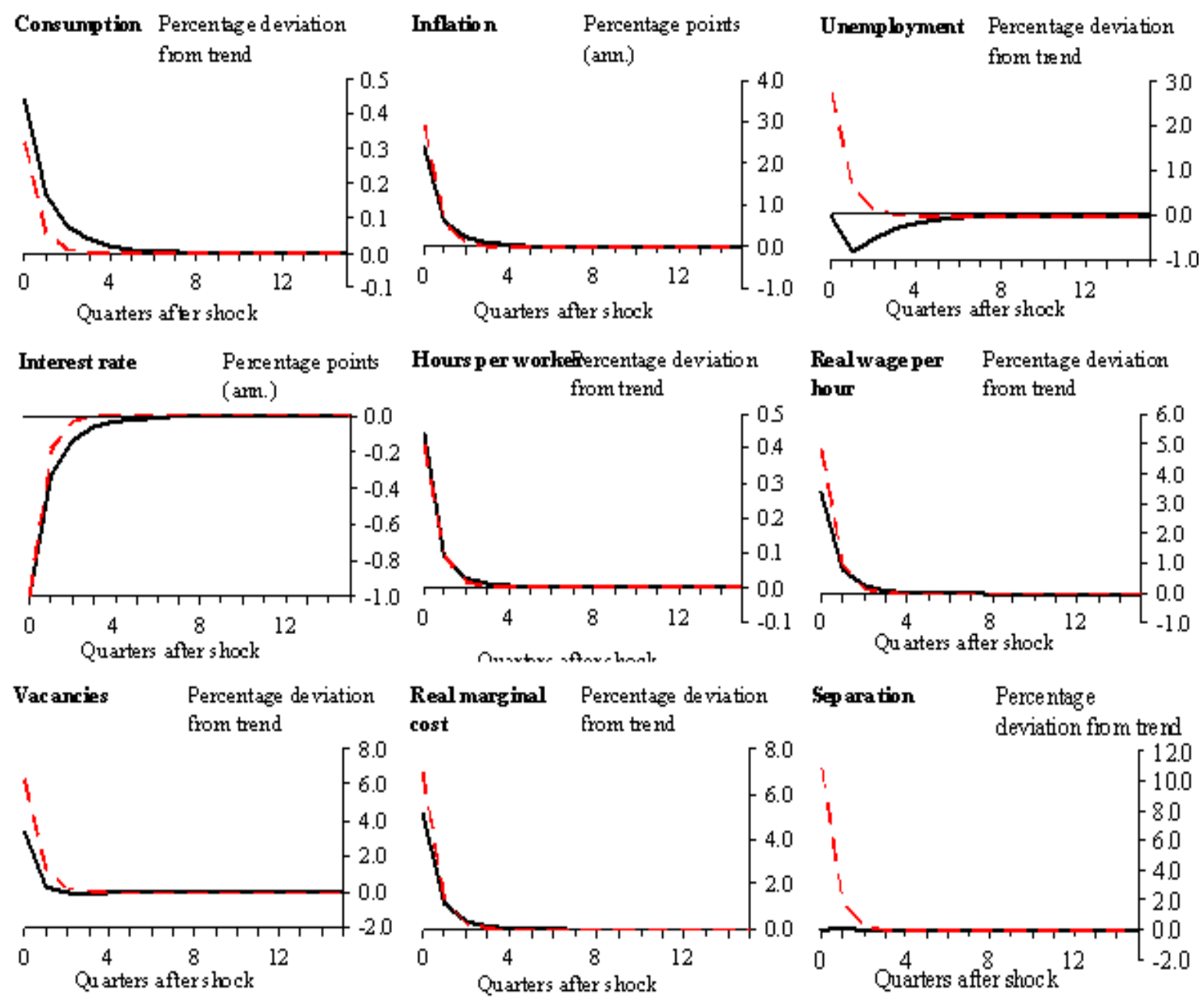

Hours per workefirercentage deviation
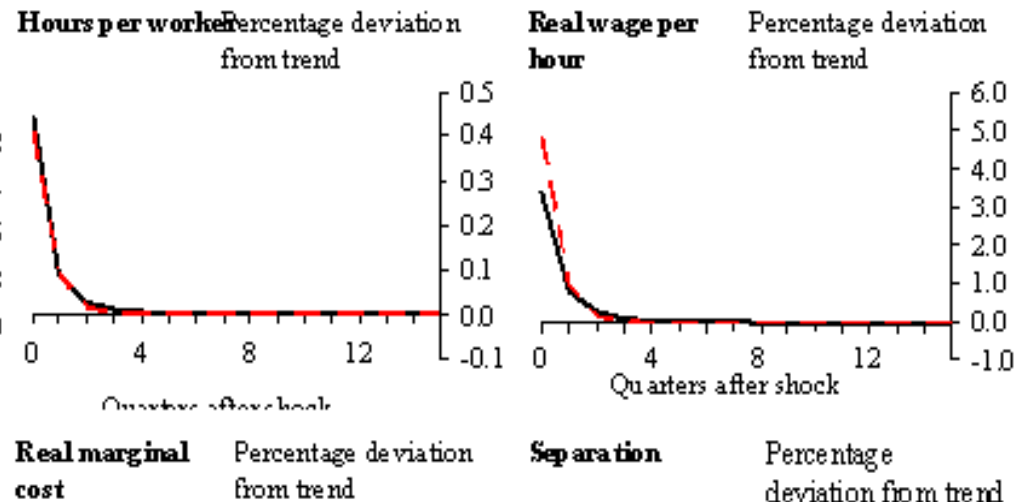

sep aration

Percentage deviation from tre rd
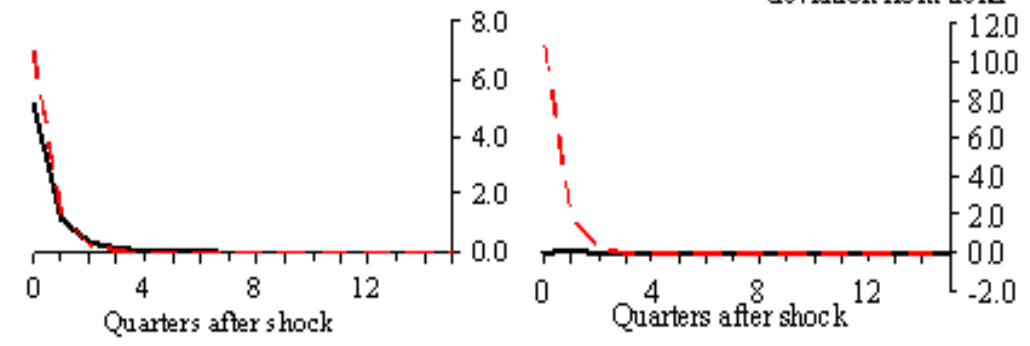

Figure 8: IMPUlSE RESPONSES TO A MONETARY EASING, MODEL WITH ENDOGENOUS SEPARATION VS. MODEL WITH EXOGENOUS SEPARATION, ALTERNATIVE CALIBRATION. Shown are impulse responses to an unanticipated 100 bps reduction in the quarterly nominal interest rate in quarter 0. All entries are in percentage deviations from steady state. Interest rates and inflation rates are reported in annualized terms. The black solid line refers to the response in a model, which features only exogenous separation between firms and workers. Apart from slight differences in the calibration (described in the main text body) this resembles the baseline model. The red dashed line marks the responses when allowing for endogenous separation. Shown is the case with a low standard deviation of the idiosyncratic technology shock, $\sigma_{z}=0.4$. 


\section{Conclusions}

In this paper, we have assessed the ability of labour market variants in a New Keynesian model to explain inflation dynamics using, as our empirical benchmark, the responses of variables to a monetary policy shock in the euro area. Our results are largely negative and are collected in Table 3 in this section. We first used a standard New Keynesian model with search and matching frictions and efficient bargaining to show that such models typically generate a response of inflation to nominal shocks that is much too large relative to the data. We then considered many, if not most, of the alternative specifications that currently exist in the literature.

\begin{tabular}{l|r|r|rr|r|r|rr}
\cline { 2 - 9 } & $\begin{array}{l}\text { Out- } \\
\text { put }\end{array}$ & $\begin{array}{l}\text { Infla- } \\
\text { tion }\end{array}$ & $\begin{array}{l}\text { Unem- } \\
\text { ploy- } \\
\text { ment }\end{array}$ & $\begin{array}{l}\text { Em- } \\
\text { ploy- } \\
\text { ment }\end{array}$ & $\begin{array}{l}\text { Real } \\
\text { wages } \\
\text { per } \\
\text { empl. }\end{array}$ & $\begin{array}{l}\text { Real } \\
\text { wage } \\
\text { per } \\
\text { hour }\end{array}$ & $\begin{array}{l}\text { Total } \\
\text { hours } \\
\text { wor- } \\
\text { ked }\end{array}$ & $\begin{array}{l}\text { Hours } \\
\text { per } \\
\text { empl- } \\
\text { oyee }\end{array}$ \\
\hline \hline Euro area data & 0.6 & 0.3 & -4.5 & 0.4 & 0.3 & 0.4 & 0.9 & 0.04 \\
\hline \hline Baseline (eff. barg.) & 0.4 & 2.3 & -0.9 & 0.1 & 3.5 & 3.1 & 0.4 & 0.4 \\
RTM bargaining & 0.4 & 2.3 & -0.3 & 0.0 & 5.2 & 4.8 & 0.4 & 0.4 \\
Sticky wages (EB) & 0.5 & 2.3 & -1.7 & 0.2 & 0.6 & 0.0 & 0.5 & 0.5 \\
Sticky wages (RTM) & 1.1 & 0.0 & -0.6 & 0.1 & 1.1 & 0.0 & 1.1 & 1.1 \\
Firm-level real rigidity & 1.01 & 0.1 & -0.3 & 0.03 & 1.03 & 0.03 & 1.02 & 1.02 \\
Contempor. hiring & 0.5 & 2.0 & -1.7 & 0.2 & 3.1 & 2.8 & 0.5 & 0.3 \\
Hiring costs (convex) & 0.5 & 2.4 & -1.1 & 0.1 & 3.6 & 3.1 & 0.5 & 0.5 \\
Hiring costs (sunk) & 0.4 & 2.4 & -0.7 & 0.1 & 3.4 & 3.0 & 0.4 & 0.4 \\
On-the-job search & 0.5 & 2.2 & -3.2 & 0.3 & 4.1 & 3.6 & 0.6 & 0.5 \\
Endog. separation & 0.3 & 2.9 & 2.8 & -0.3 & 5.2 & 4.8 & 0.1 & 0.4 \\
\hline \hline
\end{tabular}

Table 3: Peak Responses to a 100 bps monetary Easing in the models and IN THE DATA. Top: euro area data (cp. the appendix for details). Then: baseline model with efficient bargaining (EB) and right-to-manage bargaining (RTM); models with EB and RTM and sticky wages for new and existing matches; real rigidities arising at the firm-level due to firm-specific labour; contemporaneous hiring instead of a one-period lag; different forms of hiring costs (period by period but convex in the hiring rate, or sunk); on-the-job search; and allowing for endogenous separation. Relative to the baseline, each of the models changes one feature at a time. From left to right: output, inflation, unemployment, employment, real wages per employee, real wage per hour, total hours worked, hours per employee. All variables are expressed in log percentage deviation from steady state.

We first considered the addition of wage rigidity. Under efficient bargaining, wage stickiness in existing jobs has no effect, since average wages in existing jobs are nonallocative. But wage stickiness in newly created jobs does have an effect. In this case, the existing wage rate will affect real marginal cost, since the wage paid to new hires 
affects hiring incentives and, thus, marginal costs. Combined with a 'right-to-manage' assumption for the determination of hours (which implies a direct channel from wages to inflation), staggered wages at the level of the match will help to smooth the reaction of the aggregate wage, resulting in a smaller response to shocks of marginal cost and inflation. When we then combined this nominal rigidity with the real rigidity of firmspecific labour, we found that prices respond less to shocks the more any individual firm's marginal cost responds to a change in that firm's price. Hence, the response of inflation to nominal shocks is reduced if the marginal disutility of work is increasing in hours worked and/or there are decreasing returns to labour; both these conditions hold in our calibrated model.

Given the central role of employment dynamics for marginal costs, we then looked at variants of the hiring cost function that have been proposed to imply stronger and more persistent employment fluctuations. We found that neither of the modifications we considered materially affected the response of inflation to nominal shocks. Finally, we considered two other margins along which adjustment can occur in the labour market: on-the-job search and endogenous job destruction. We found that both features could help reduce the response of inflation to shocks. However, the effects were not particularly strong. In addition, the effects of endogenising job destruction depend critically on the calibration of the model, and some of the implications for other model variables were counterfactual.

In summary, we found that a model with sticky nominal wages when combined with right-to-manage bargaining was best able to capture the response of inflation to nominal shocks. Reassuringly, in that setup it was also largely irrelevant whether wage stickiness affected only existing matches or also new matches. More generally, our results suggest that the extent to which the labour market matters for inflation dynamics depends crucially on its microeconomic structure.

For future work, it would therefore be interesting to test the mechanisms we have explored using microeconomic data. Work on wage stickiness for new hires that has recently been conducted, e.g., by Haefke et al. (2008) is a first step in that direction. Microeconomic evidence on bargaining, and contractual arrangements regarding state contingency of the wage, overtime payments and premia, overtime accounts and nonwage components of compensation would be a valuable further step toward assessing the relative merits of these different labour market setups. 


\section{References}

[1] Akerlof, G, Rose, A, and Yellen, J (1988), 'Job switching and job satisfaction in the US labour market', Brookings Papers on Economic Activity, Vol. 2, pages 495-594.

[2] Alvarez, L, Dhyne, E, Hoeberichts, M, Kwapil, C, Le Bihan, H, Lünnemann, P, Martins, F, Sabbatini, R, Stahl, H, Vermeulen, P, and Vilmunen J (2006), 'Sticky prices in the euro area: a summary of new micro evidence', Journal of the European Economic Association, Vol. 4, pages 575-84.

[3] Angeloni, I, Kashyap, A, Mojon, B, and Terlizzese, D (2003), 'The output composition puzzle: a difference in the monetary transmission mechanism in the euro area and United States', Journal of Money, Credit, and Banking, Vol. 35, pages 1265-306.

[4] Ball, L, and Romer, D (1990), 'Real rigidities and the non-neutrality of money', Review of Economic Studies, Vol. 57, pages 183-203.

[5] Bernanke, B, Boivin, J, and Eliasz, P (2005), 'Measuring the effects of monetary policy: a factor-augmented vector autoregressive (FAVAR) approach', Quarterly Journal of Economics, Vol. 120, pages 387-422.

[6] Blanchard, O, and Gali, J (2006), 'A New Keynesian model with unemployment', National Bank of Belgium Working Paper No. 92.

[7] Blanchard, O, and Gali, J (2007), 'Real wage rigidities and the New Keynesian model', Journal of Money, Credit and Banking, Vol. 39, pages 35-65.

[8] Bodart, V, de Walque, G, Pierrard, O, Sneessens, H, and Wouters, $\mathbf{R}$ (2006), 'Nominal wage rigidities in a New Keynesian model with frictional unemployment', IZA Discussion Paper No. 2528.

[9] Bodart, V, Pierrard, O, and Sneessens, H (2005), 'Calvo wages in a search unemployment model', DNB Working Paper No. 68.

[10] Burda, M, and Wyplosz, C (1994), 'Gross worker and job flows in Europe' European Economic Review, Vol. 38, pages 1287-315.

[11] Christiano, L, Eichenbaum, M, and Evans, C (2005), 'Nominal rigidities and the dynamic effects of a shock to monetary policy', Journal of Political Economy, Vol. 113, pages 1-45. 
[12] Christoffel, K, Kuester, K, and Linzert, T (2009), 'The role of labor markets for euro area monetary policy', FRB Philadelphia Working Paper No. 09-01.

[13] Christoffel, K, and Linzert, T (2005), 'The role of real wage rigidity and labor market frictions for unemployment and inflation dynamics', ECB Working paper No. 556.

[14] Christoffel, K, and Kuester, K (2008), 'Resuscitating the wage channel in models with unemployment fluctuations', Journal of Monetary Economics, Vol. $55(5)$, pages $865-887$

[15] Contini, B, and Revelli, R (1997), 'Gross flows vs. net flows in the labour market: What is there to be learned?', Labour Economics, Vol. 4, pages 245-63.

[16] den Haan, W, Ramey, G, and Watson, J (2000), 'Job destruction and propagation of shocks', American Economic Review, Vol. 90, pages 482-98.

[17] du Caju, P, Gautier, E, Momferatou, D, and Ward-Warmedinger, M (2008), 'Institutional features of wage bargaining in $22 \mathrm{EU}$ countries, the US and Japan', European Central Bank Working Paper No. 974.

[18] Erceg, C., Henderson, D., and Levin, A. (2000), 'Optimal monetary policy with staggered wage and price contracts,' Journal of Monetary Economics, Vol. 46(2), pages 281-313.

[19] Evers, M, Mooij, R A D, and Vuuren, D J V (2005), 'What explains the variation in estimates of labour supply elasticities?', CESifo Working Paper No. 1633.

[20] Faia, E (2008), 'Optimal monetary policy rules with labour market frictions', Journal of Economic Dynamics and Control, Vol. 32(5), pages 1600-621.

[21] Fujita, S, and Ramey, G (2007), 'Job matching and propagation,' Journal of Economic Dynamics and Control, .Vol 31(11), pages 3671-98.

[22] Fujita, S, and Ramey, G (2008), 'The cyclicality of separation and job finding rates', forthcoming International Economic Review.

[23] Gertler, M and Trigari, A (2006), 'Unemployment fluctuations with staggered Nash wage bargaining', NBER Working Paper No. 12498.

[24] Gomes, P (2008), 'Labour market flows: facts from the UK', London School of Economics, mimeo. 
[25] Haefke, C, Sonntag, M, and van Rens, T (2008), 'Wage rigidity and job creation ', IZA Discussion Paper No. 3714.

[26] Hall, R E (2005), 'Employment fluctuations with equilibrium wage stickiness', American Economic Review, Vol. 95, pages 50-65.

[27] Hobijn, B, and Sahin, A (2007), 'Job-finding and separation rates in the OECD', Federal Reserve Bank of New York Staff Report No. 298.

[28] Krause, M, and Lubik, T (2006), 'The cyclical upgrading of labour and onthe-job search', Labour Economics, Vol. 13, pages 459-77.

[29] Krause, M, and Lubik, T (2007), 'The (ir)relevance of real wage rigidity in the New Keynesian model with search frictions', Journal of Monetary Economics, Vol. 54, pages 706-27.

[30] Kuester, K (2007), 'Real price and wage rigidities in a model with matching frictions', European Central Bank Working Paper No. 720.

[31] McCallum, A, and Smets, F (2008), 'Real wages and monetary policy transmission in the euro area', European Central Bank, mimeo.

[32] Merz, M (1995), 'Search in the labour market and the real business cycle', Journal of Monetary Economics, Vol. 36, pages 269-300.

[33] Mojon, B, and Peersman, G (2003), 'A VAR description of the effects of monetary policy in the individual countries of the euro area', in I. Angeloni, A. Kashyap, and B. Mojon (eds.) Monetary Policy Transmission in the Euro Area, Cambridge, United Kingdom: Cambridge University Press.

[34] Mortensen, D, and Pissarides, C A (1994), 'Job creation and job destruction in the theory of unemployment', Review of Economic Studies, Vol. 61, pages 397415 .

[35] Mortensen, D, and Pissarides, C A (1999), 'Job reallocation, employment fluctuations and unemployment', in J. Taylor and M. Woodford (eds.) Handbook of Macroeconomics, Vol. 1, pages 1171-228. Amsterdam: North-Holland.

[36] Normandin, M (2006), 'The effects of monetary-policy shocks on real wages: A multi-country investigation', Institut d'économie appliquée HEC Montréal Cahiers de recherche No. 06-04. 
[37] Peersman, G, and Smets, F (2003), 'The monetary transmission mechanism in the euro area: More evidence from VAR analysis', in I. Angeloni, A. Kashyap, and B. Mojon (eds.) Monetary Policy Transmission in the Euro Area, Cambridge, United Kingdom: Cambridge University Press.

[38] Peersman, G, and Straub, R (2007), 'Putting the New Keynesian model to a test', European Central Bank, mimeo.

[39] Petrongolo, B, and Pissarides, C A (2001), 'Looking into the black box: A survey of the matching function', Journal of Economic Literature, Vol. 39, pages 390-431.

[40] Phillips, A W (1958), 'The relation between unemployment and the rate of change of money wage rates in the United Kingdom, 1861-1957', Economica, Vol. 25, pages 283-99.

[41] Pissarides, C A (2007), 'The unemployment volatility puzzle: Is wage stickiness the answer?', Econometrica, forthcoming.

[42] Ravenna, F, and Walsh, C (2008), 'Vacancies, unemployment and the Phillips curve', European Economic Review, Vol. 52(8), pages 1494-521.

[43] Shimer, R (2005), 'The cyclical behaviour of equilibrium unemployment and vacancies', American Economic Review, Vol. 95, pages 25-49.

[44] Smets, F, and Wouters, R (2003): 'An estimated stochastic dynamic general equilibrium model of the euro area', Journal of the European Economic Association, Vol. 1, pages 1123-75.

[45] Sveen, T, and Weinke, L (2007), 'Inflation dynamics and labour market dynamics revisited', Kiel Institute for the World Economy Working Paper No. 1368.

[46] Tang, J-H (2006), 'Optimal monetary policy in a New Keynesian model with job search', National Tsing-Hua University, Taiwan, mimeo.

[47] Thomas, C (2008), 'Search frictions, real rigidities and inflation dynamics', Banco de España Working Paper No. 0806.

[48] Trigari, A (2006), 'The role of search frictions and bargaining for inflation dynamics', IGIER Working Paper No. 304.

[49] Trigari, A (2009), 'Equilibrium unemployment, job flows, and inflation dynamics', Journal of Money, Credit and Banking, Vol. 41(1), pages 1-33. 
[50] van Zandweghe, W (2009), 'On-the-job search, sticky prices and persistence', FRB Kansas City Working Paper 09-03.

[51] Walsh, C. (2005), 'Labour market search, sticky prices, and interest rate policies', Review of Economic Dynamics, Vol. 8, pages 829-49.

[52] Woodford, M (2003), Interest and Prices, Princeton: Princeton University Press.

[53] Yashiv, E (2006), 'Evaluating the performance of the search and matching model', European Economic Review, Vol. 50, pages 909-36.

[54] Zanetti, F (2007), 'Labour market institutions and aggregate fluctuations in a search and matching model', Bank of England Working Paper No. 333.

\section{Appendix A: further evidence on monetary trans- mission in the euro area}

In the paper, we benchmarked the different approaches to modelling the labour market against five stylised facts about the transmission of monetary policy in the euro area. This section presents the background evidence from which we deduced these stylised facts. ${ }^{32}$ Figure 9 prints the impulse responses of euro area aggregates to a 100-basispoint monetary shock (an easing) in McCallum and Smets (2008), who estimate a factor-augmented VAR following the methodology of Bernanke et al. (2005). ${ }^{33}$ Also shown are the boundaries of bootstrapped $90 \%$ confidence intervals. A monetary easing stimulates the economy. According to this evidence, at its peak output has risen by about $0.8 \%$ above steady state. Inflation increases, too, but in a muted manner. The peak increase in quarter-on-quarter GDP deflator inflation is about 25 basis points (in annualised terms). As a consequence of higher demand, the number of unemployed people, i.e., unemployment, falls by $3 \% .^{34}$ The increase in economic

\footnotetext{
${ }^{32} \mathrm{~A}$ number of studies have examined the response of real and nominal variables in the euro area to a monetary shock using alternative identification mechanisms. For early evidence on the euro area as a whole see, e.g., Peersman and Smets (2003) and Angeloni et al. (2003). More recent papers are McCallum and Smets (2008) and Peersman and Straub (2007). For evidence country by country, see, e.g., Mojon and Peersman (2003) and Normandin (2006).

${ }^{33}$ Their data comprise quarterly euro area aggregates and a number of euro-area country-specific series from 1987Q1 to 2005Q4, as well as foreign series.

${ }^{34}$ The depicted fall in unemployment corresponds to a fall in the unemployment rate of about 0.27 percentage point. Unemployment is calculated in a model-consistent way from the response in employment, which McCallum and Smets report, by assuming that the labor force does not react to a monetary easing and that average unemployment rates are $9 \%$.
} 

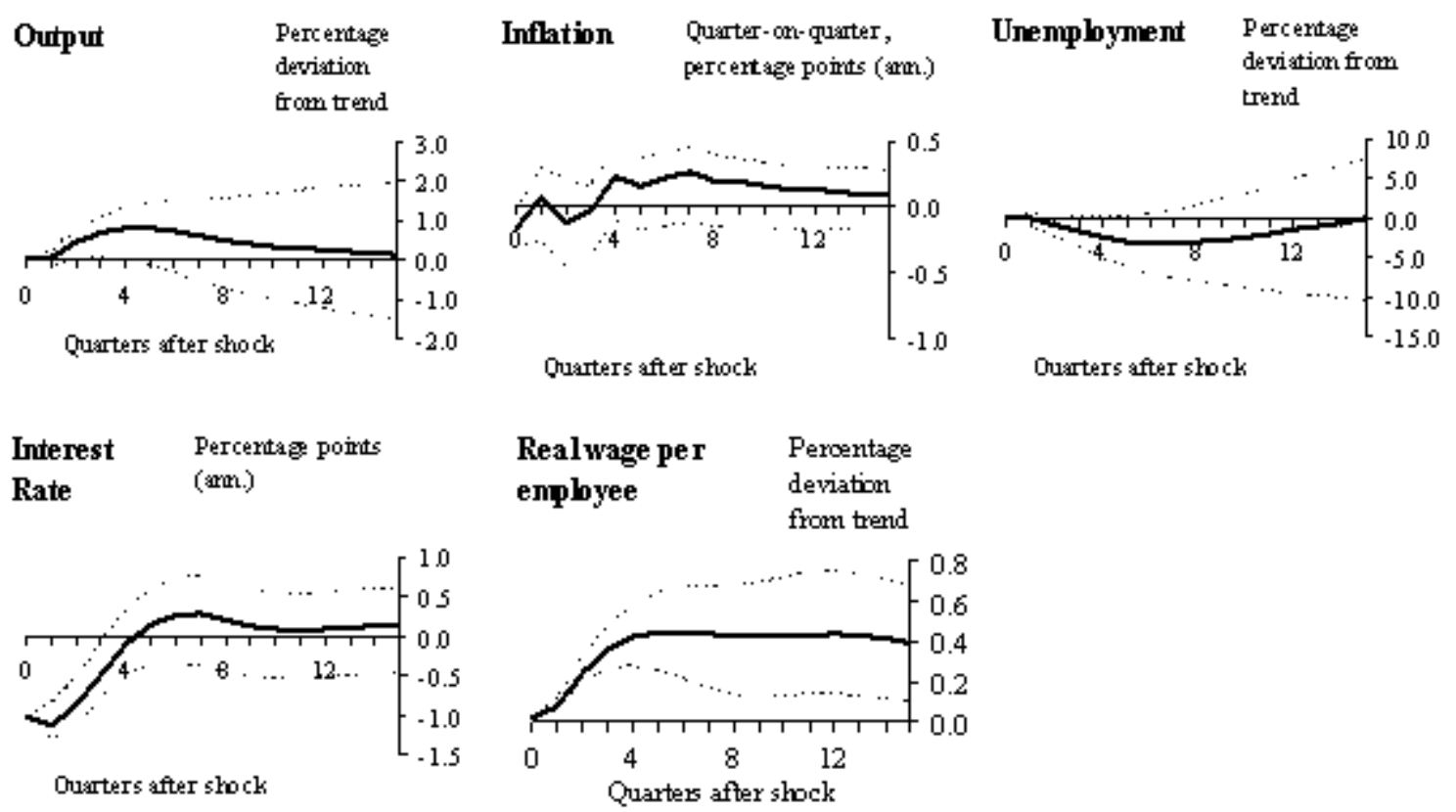

Figure 9: Impulse Responses to An UnANTICIPATEd MONETARY SHOCK IN THE euro area, source: McCallum and Smets (2008). Depicted are responses to a 100 bps monetary easing (annualized nominal rates). Charts refer to the euro area. The sample is 1987Q1 to 2005Q4. Top row (from left to right): response of real GDP (in percentage deviation from trend), quarter-on-quarter GDP inflation (in annualized percentage points), unemployment (in percentage deviation from trend). Note: shown is the response of $\log$ unemployment (heads), $\log (\mathrm{ut}$ ). Bottom row: response of nominal interest rate (in annualized percentage points) and the real wage per employee (in percentage deviation from trend). Reprinted with the authors' permission.

activity also translates into an increase in the real wage per employee. That increase is about half the size of the increase in output but is highly persistent.

Complementing this evidence, Figure 10 reports our own estimates of the monetary transmission in the euro area. The sample starts in 1987Q1, as in McCallum and Smets (2008), and runs through 2006Q4. We estimated a standard VAR(4) in the variables shown in the graphs and identified the monetary shock through the oft-used recursive ordering scheme. For details see the notes to Figure 10. According to these estimates, an unanticipated monetary easing induces a longer-lived deviation of nominal rates from the baseline than in McCallum and Smets (2008) and, as a result, most responses are more persistent. With regard to amplitudes, the evidence above is robust. A monetary easing of 100 basis points causes a significant increase in output of about $0.8 \%$ at its peak, and an increase in real wages per employee of about half that size (which is, again, highly persistent). Unemployment, according to our estimates, falls by $6 \% .^{35}$ At the same time, the increase in inflation remains contained, with

\footnotetext{
${ }^{35}$ This translates into a reduction in the unemployment rate of about 0.54 percentage points.
} 


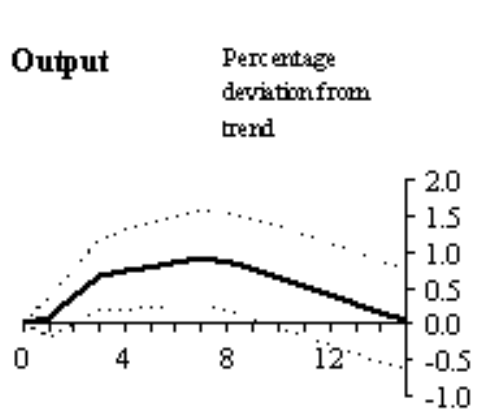

Quarters after shock

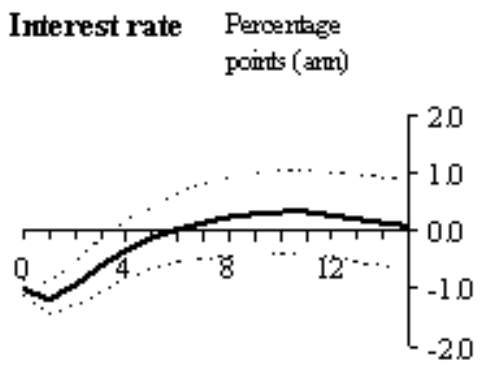

Quarters after shock
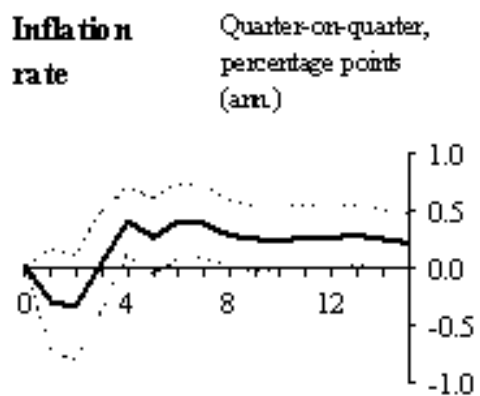

Quartes after shock
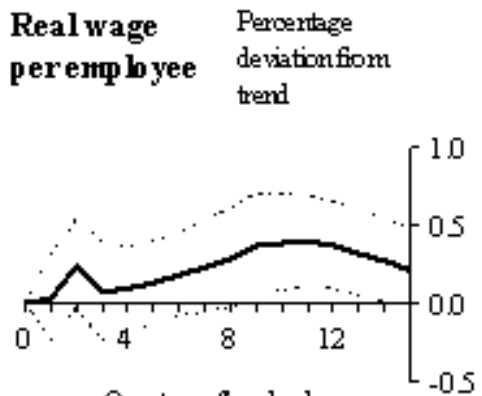

Quartes affer shock
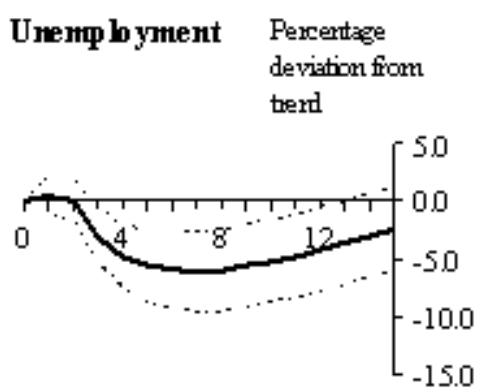

Quarter affer shock

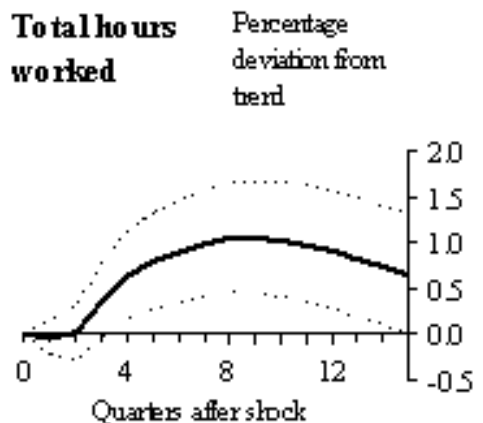

Figure 10: IMPUlSE RESPONSES TO AN UNANTICIPATED MONETARY SHOCK - OWN ESTIMATES. Underlying the results is a $\operatorname{VAR}(4)$ estimated on above data (taken from the AWM data set except for hours worked, which is taken from Christoffel et al., 2009). The sample is 1987Q1 to 2006Q4; identification relies on the usual Cholesky decomposition. The data were de-trended variable by variable prior to running the VAR. For real variables, we allow for a trend, and a break in the trend plus a level shift in 1991Q1 so as to accommodate German reunification. Inflation and nominal interest rates were regressed on a linear trend, which breaks after 1998Q4 in order to account for the disinflation in the euro area prior to the introduction of the common currency, and the constancy of the inflation objective thereafter. Dotted lines mark asymptotic $90 \%$ confidence intervals $(5 \%$ and $95 \%$ bounds).

GDP deflator inflation remaining below 0.4 percentage point in annualised terms.

In the above estimation, we resort to the same proxy for hours worked in the euro area as used by Christoffel et al. (2009). ${ }^{36}$ When using this series to infer hourly wage rates and hours worked per employee, the results suggest that changes at the extensive margin are more relevant for labour adjustment than hours worked per employee. The first two panels of Figure 11 suggest that hours worked per employee react little throughout the period (and if anything, they fall), while the number of employees is more responsive. As a result, the increase in wages per employee depicted in Figure 10 is mainly attributed to a slow but persistent increase in hourly wages instead of an

\footnotetext{
${ }^{36}$ Unfortunately, harmonized quarterly series for hours worked do not exist for the euro area. The proxy uses the quarterly real GDP series for the euro area to interpolate annual EU-Klems data on total hours worked in the euro area.
} 

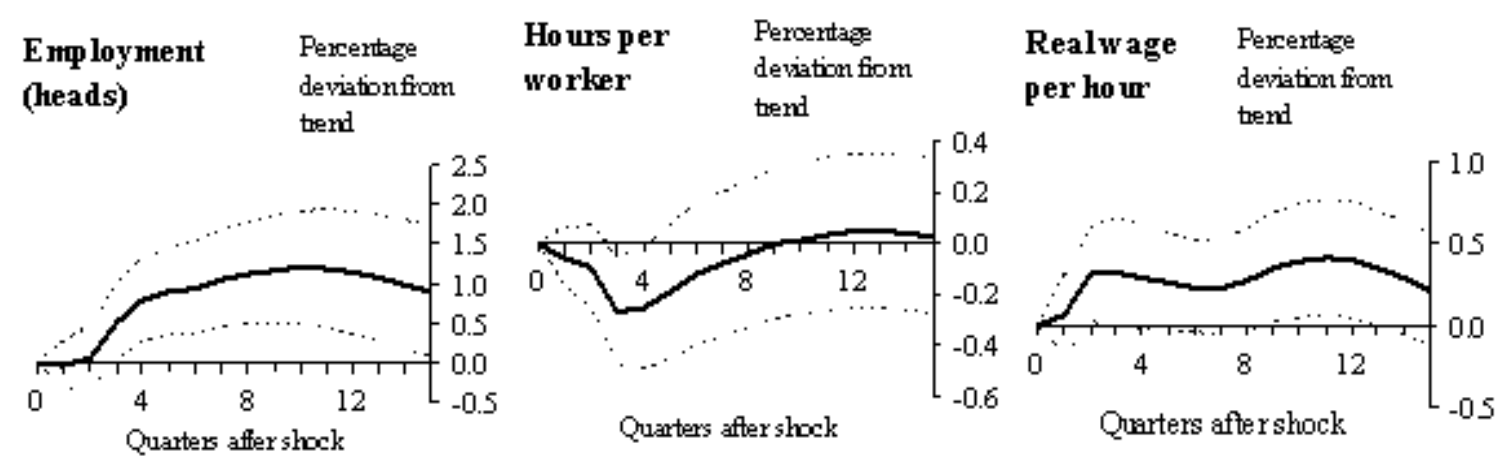

Figure 11: ImpUlse RESPONSES OF HOURS AND WAGES TO A MONETARY SHOCK OWN ESTIMATES. Shown are the responses of employment, hours per employee and the real wage rate. The VAR is the same as in Figure 10, except that the measures of hours per worker and of the real hourly wage rate replace the measures for total hours worked and the real wage per employee.

increase in hours per worker. (See Figure 11.) Due to the limitations of the euro area data with respect to hours worked or hourly wages, however, the responses in Figure 11 - while indicative - should be taken with some caution.

Finally, Table 4 summarises the impulse responses reported above and augments these with the evidence of three further studies. Angeloni et al. (2003) report impulse responses for the euro area based on various identification schemes for the monetary shock in a VAR. So do Peersman and Smets (2003). The table, in addition, collects evidence of a recent study by Peersman and Straub (2007), who identify a monetary shock (and other shocks) based on sign restrictions, which were derived from a prototypical New Keynesian model. The table summarises the maximum amplitudes of the variables following the monetary shock. Most of the studies imply that after the initial shock, nominal rates fall somewhat further before being tightened. In order to harmonise the studies, all responses have been normalised by the maximum easing of the nominal interest rate that these studies report. 


\begin{tabular}{l|l|c|c|c|l|l|l|c|}
\cline { 2 - 9 } & $\begin{array}{l}\text { Out- } \\
\text { put }\end{array}$ & Infl. & $\begin{array}{l}\text { Un- } \\
\text { empl. }\end{array}$ & Empl. & $\begin{array}{l}\text { Real } \\
\text { wages } \\
\text { per } \\
\text { empl. }\end{array}$ & $\begin{array}{l}\text { Real } \\
\text { wage } \\
\text { per } \\
\text { hour }\end{array}$ & $\begin{array}{l}\text { Total } \\
\text { hours } \\
\text { wor- } \\
\text { ked }\end{array}$ & $\begin{array}{l}\text { Hours } \\
\text { per } \\
\text { empl. }\end{array}$ \\
\hline \hline McCallum,Smets (1) & 0.7 & 0.2 & -2.9 & 0.3 & 0.4 & - & - & - \\
Own VAR (2) & 0.6 & 0.3 & -4.5 & 0.4 & 0.3 & 0.4 & 0.9 & 0.04 \\
Peersman,Straub (3) & 0.3 & 0.2 & -2.8 & 0.3 & 0.3 & 0.3 & 0.3 & 0 \\
Angeloni et al. (4) & 0.5 & 0.2 & -3.3 & 0.3 & - & - & - & - \\
Peersman,Smets (5) & 0.5 & 0.2 & -3.3 & 0.3 & - & - & - & - \\
\hline \hline
\end{tabular}

Table 4: Peak responses to a monetary easing in the literature. Most of the studies imply that after the initial easing, nominal rates fall somewhat further before they tighten. In order to harmonize the studies, all responses have been normalized by the maximum easing of the nominal interest rate that these studies report (which in all studies occurs one quarter after the shock). Entries in small type refer to numbers that have been deduced indirectly as described below. (1): McCallum and Smets (2008) report the response of employment. The response for unemployment is inferred from the figure for employment assuming a constant labor force and an average unemployment rate of 9\%. (2): Own VAR: hours worked data for the euro areaare subject to measurement errors as stated in the main text. (3): Peersman and Straub (2007) only report the response of total hours worked but state that responses are similar when employment is used. We thus report the same response of employment as for total hours worked. The response for unemployment is inferred as in (1). Similarly, hourly wage rates and hours per employee are inferred from this statement. (4): Peersman and Smets (2003): sample 1980-1998. Entries are based on their Fig. 2.1 and Fig. 2.8. The response for unemployment is inferred as in note (1). (5): Angeloni et al. (2003) report the response of the unemployment rate (see their Table 6). The response of unemployment reported here is obtained using an unemployment rate of $9 \%$. Figures for employment were obtained accordingly. Results for the Angeloni et al. paper are averages over different specifications for the sample 1980-2001. Only the response of consumer prices is reported. Results were read off the figures and tables in their paper. 


\section{European Central Bank Working Paper Series}

For a complete list of Working Papers published by the ECB, please visit the ECB's website (http://www.ecb.europa.eu).

1002 "Assessing portfolio credit risk changes in a sample of EU large and complex banking groups in reaction to macroeconomic shocks" by O. Castrén, T. Fitzpatrick and M. Sydow, February 2009.

1003 "Real wages over the business cycle: OECD evidence from the time and frequency domains" by J. Messina, C. Strozzi and J. Turunen, February 2009.

1004 "Characterising the inflation targeting regime in South Korea" by M. Sánchez, February 2009.

1005 "Labor market institutions and macroeconomic volatility in a panel of OECD countries" by F. Rumler and J. Scharler, February 2009.

1006 "Understanding sectoral differences in downward real wage rigidity: workforce composition, institutions, technology and competition" by P. Du Caju, C. Fuss and L. Wintr, February 2009.

1007 "Sequential bargaining in a new-Keynesian model with frictional unemployment and staggered wage negotiation" by G. de Walque, O. Pierrard, H. Sneessens and R. Wouters, February 2009.

1008 “Liquidity (risk) concepts: definitions and interactions” by K. Nikolaou, February 2009.

1009 “Optimal sticky prices under rational inattention” by B. Maćkowiak and M. Wiederholt, February 2009.

1010 "Business cycles in the euro area" by D. Giannone, M. Lenza and L. Reichlin, February 2009.

I0II "The global dimension of inflation - evidence from factor-augmented Phillips curves" by S. Eickmeier and K. Moll, February 2009.

1012 "Petrodollars and imports of oil exporting countries" by R. Beck and A. Kamps, February 2009.

1013 "Structural breaks, cointegration and the Fisher effect" by A. Beyer, A. A. Haug and B. Dewald, February 2009.

1014 "Asset prices and current account fluctuations in G7 economies" by M. Fratzscher and R. Straub, February 2009.

1015 "Inflation forecasting in the new EU Member States" by O. Arratibel, C. Kamps and N. Leiner-Killinger, February 2009.

1016 "When does lumpy factor adjustment matter for aggregate dynamics?" by S. Fahr and F. Yao, March 2009.

1017 "Optimal prediction pools" by J. Geweke and G. Amisano, March 2009.

1018 "Cross-border mergers and acquisitions: financial and institutional forces" by N. Coeurdacier, R. A. De Santis and A. Aviat, March 2009.

1019 "What drives returns to euro area housing? Evidence from a dynamic dividend-discount model" by P. Hiebert and M. Sydow, March 2009.

1020 "Opting out of the Great Inflation: German monetary policy after the break down of Bretton Woods" by A. Beyer, V. Gaspar, C. Gerberding and O. Issing, March 2009.

102I "Rigid labour compensation and flexible employment? Firm-level evidence with regard to productivity for Belgium" by C. Fuss and L. Wintr, March 2009. 
1022 "Understanding inter-industry wage structures in the euro area” by V. Genre, K. Kohn and D. Momferatou, March 2009.

1023 "Bank loan announcements and borrower stock returns: does bank origin matter?" by S. Ongena and V. Roscovan, March 2009.

1024 "Funding liquidity risk: definition and measurement" by M. Drehmann and K. Nikolaou, March 2009.

1025 "Liquidity risk premia in unsecured interbank money markets" by J. Eisenschmidt and J. Tapking, March 2009.

1026 "Do house price developments spill over across euro area countries? Evidence from a global VAR” by I. Vansteenkiste and P. Hiebert, March 2009.

1027 “Long run evidence on money growth and inflation” by L. Benati, March 2009.

1028 "Large debt financing: syndicated loans versus corporate bonds" by Y. Altunbaș, A. Kara and D. Marqués-lbáñez, March 2009.

1029 "The role of fiscal transfers for regional economic convergence in Europe" by C. Checherita, C. Nickel and P. Rother, March 2009.

1030 "Forecast evaluation of small nested model sets" by K. Hubrich and K. D. West, March 2009.

I03I “Global roles of currencies” by C. Thimann, March 2009.

1032 “Assessing long-term fiscal developments: a new approach” by A. Afonso, L. Agnello, D. Furceri and R. Sousa, March 2009.

1033 "Fiscal competition over taxes and public inputs: theory and evidence" by S. Hauptmeier, F. Mittermaier and J. Rincke, March 2009.

1034 "The role of the United States in the global economy and its evolution over time" by S. Dées and A. Saint-Guilhem, March 2009.

1035 "The role of labor markets for euro area monetary policy" by K. Christoffel, K. Kuester and T. Linzert, March 2009.

1036 "Search in the product market and the real business cycle" by T. Y. Mathä and O. Pierrard, March 2009.

1037 "What do asset prices have to say about risk appetite and uncertainty?" by G. Bekaert, M. Hoerova and M. Scheicher, March 2009.

1038 “Are 'intrinsic inflation persistence' models structural in the sense of Lucas (I976)?” by L. Benati, March 2009.

1039 “'Real Time’ early warning indicators for costly asset price boom/bust cycles: a role for global liquidity” by L. Alessi and C. Detken, March 2009.

1040 "The external and domestic side of macroeconomic adjustment in China" by R. Straub and C. Thimann, March 2009.

104I "An economic capital integrating credit and interest rate risk in the banking book" by P. Alessandri and M. Drehmann, April 2009.

1042 “The determinants of public deficit volatility” by L. Agnello and R. M. Sousa, April 2009.

1043 "Optimal monetary policy in a model of the credit channel” by F. De Fiore and O. Tristani, April 2009. 
1044 "The forecasting power of international yield curve linkages" by M. Modugno and K. Nikolaou, April 2009.

1045 "The term structure of equity premia in an affine arbitrage-free model of bond and stock market dynamics" by W. Lemke and T. Werner, April 2009.

1046 "Productivity shocks and real exchange rates: a reappraisal" by T. A. Peltonen and M. Sager, April 2009.

1047 "The impact of reference norms on inflation persistence when wages are staggered" by M. Knell and A. Stiglbauer, April 2009.

1048 “Downward wage rigidity and optimal steady-state inflation” by G. Fagan and J. Messina, April 2009.

1049 "Labour force participation in the euro area: a cohort based analysis" by A. Balleer, R. Gómez-Salvador and J. Turunen, May 2009.

1050 "Wealth effects on consumption: evidence from the euro area" by R. M. Sousa, May 2009.

105I "Are more data always better for factor analysis? Results for the euro area, the six largest euro area countries and the UK" by G. Caggiano, G. Kapetanios and V. Labhard, May 2009.

1052 "Bidding behaviour in the ECB's main refinancing operations during the financial crisis" by J. Eisenschmidt, A. Hirsch and T. Linzert, May 2009.

1053 "Inflation dynamics with labour market matching: assessing alternative specifications” by K. Christoffel, J. Costain, G. de Walque, K. Kuester, T. Linzert, S. Millard and O. Pierrard, May 2009. 
